\title{
Collagen VI Deficiency Results in Structural Abnormalities in the Mouse Lung
}

Jared A. Mereness, ${ }^{* \dagger}$ Soumyaroop Bhattacharya, ${ }^{*}$ Yue Ren, ${ }^{*}$ Qian Wang, ${ }^{*}$ Christopher S. Anderson, * Kathy Donlon, * Andrew M. Dylag, ${ }^{*}$ Jeannie Haak, ${ }^{*}$ Alessia Angelin, ${ }^{\ddagger}$ Paolo Bonaldo, ${ }^{\S}$ and Thomas J. Mariani ${ }^{* \dagger}$

From the Division of Neonatology and Pediatric Molecular and Personalized Medicine Program,* Department of Pediatrics, and the Department of Biomedical Genetics, ${ }^{\dagger}$ University of Rochester, Rochester, New York; the Center for Mitochondrial and Epigenomic Medicine, ${ }^{\ddagger}$ Children's Hospital of Philadelphia Research Institute, Philadelphia, Pennsylvania; and the Department of Molecular Medicine, ${ }^{\S}$ University of Padova, Padova, Italy

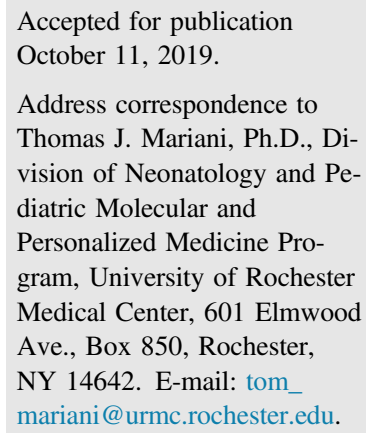

\begin{abstract}
Collagen VI (COL6) is known for its role in a spectrum of congenital muscular dystrophies, which are often accompanied by respiratory dysfunction. However, little is known regarding the function of COL6 in the lung. We confirmed the presence of COL6 throughout the basement membrane region of mouse lung tissue. Lung structure and organization were studied in a previously described Col6a1 ${ }^{-}-$mouse, which does not produce detectable COL6 in the lung. The Col6a1-/- mouse displayed histopathologic alveolar and airway abnormalities. The airspaces of Col6a1 ${ }^{-/}$lungs appeared simplified, with larger $(29 \% ; P<0.01)$ and fewer $(31 \% ; P<0.001)$ alveoli. These airspace abnormalities included reduced isolectin $\mathrm{B}^{+}$alveolar capillaries and surfactant protein $\mathrm{C}$-positive alveolar epithelial type-II cells. Alterations in lung function consistent with these histopathologic changes were evident. Col6a1 ${ }^{-/-}$ mice also displayed multiple airway changes, including increased branching $(59 \% ; P<0.001)$, increased mucosal thickness $(34 \% ; P<0.001)$, and increased epithelial cell density $(13 \% ; P<0.001)$. Comprehensive transcriptome analysis revealed that the loss of COL6 is associated with reductions in integrin-paxillin-phosphatidylinositol 3-kinase signaling in vivo. In vitro, COL6 promoted steady-state phosphorylated paxillin levels and reduced cell density $(16 \%$ to $28 \% ; P<0.05)$ at confluence. Inhibition of phosphatidylinositol 3-kinase, or its downstream effectors, resulted in increased cell density to a level similar to that seen on matrices lacking COL6. (Am J Pathol 2020, 190: 426-441; https:// doi.org/10.1016/j.ajpath.2019.10.014)
\end{abstract}

The extracellular matrix (ECM) is composed of the noncellular components of a tissue and provides multiple critical structural and signaling properties. Major components of the ECM include collagens, proteoglycans, glycoproteins, elastin, and fibronectin. Highly diverse organization of the ECM contributes a broad range of properties, including tissue stiffness and elasticity, to facilitate proper tissue and organ function. ${ }^{1-3}$ In addition to structural properties, ECM can provide numerous signaling cues for events, including migration, proliferation, and differentiation, to direct development, healing, and homeostatic conditions. ${ }^{4,5}$ This can be accomplished via direct interaction of cells with the matrix or by sequestration and release or presentation of growth factors by the matrix. Disruption of any of the functions of the ECM can be devastating to the tissue and is known to be involved in a multitude of diseases. ${ }^{6}$
The ECM is known to be critical in the development, organization, and maintenance of lung structure. During development and homeostasis, organization and presence of particular ECM components direct both cellular function and further remodeling and maturation of the matrix by the surrounding cells. This can be due to cell signaling initiated by interaction with matrix components or mechanotransduction, a process by which cells respond to the mechanical forces

Supported by the University of Rochester Pulmonary Training grant 5 T32 HL 66988-14 (J.A.M.), the University of Rochester Howard Hughes Medical Institute Fellowship in Translational Cardiovascular Research (J.A.M.), Molecular Atlas of Lung Development Program Human Tissue Core HL122700 (T.J.M.), and the Pediatric Molecular and Personalized Medicine Program (T.J.M.).

Disclosures: None declared. 
imparted by the matrix. ${ }^{7-9}$ Alterations in the structure and expression of collagens and elastin, critical components of the lung ECM, are associated with alveolar simplification and emphysema in the lung parenchyma. ${ }^{10-12}$ It has been shown that airway branching can also be promoted or arrested by alteration of the surrounding matrix. ${ }^{13,14}$ Changes in the matrix during development, injury repair, or homeostasis have the potential to significantly alter lung structure, and often accompany chronic lung disease. ${ }^{15,16}$

Within the matrix are specialized structures and regions. One of these structures is the basement membrane, which is found beneath the epithelium, endothelium, and other cellular structures, including muscle and adipose. ${ }^{17}$ The basement membrane is canonically composed of multiple collagens, the best-known being collagen IV, as well as fibronectin, laminin, and entactin, but can include many additional matrix proteins and proteoglycans. ${ }^{17,18}$ The highly epithelial nature of the lung, and extent of vascularization, leads to an abundance of basement membrane throughout much of the overall lung structure. The basement membrane plays a crucial role in the structural organization and regulation of pulmonary epithelial cell function. ${ }^{19,20}$ There is substantial dysregulation, and in some cases, a pathologic role of the lung basement membrane in several diseases, including chronic obstructive pulmonary disease, idiopathic pulmonary fibrosis, and bronchopulmonary dysplasia (BPD). Structural defects are known pathologies in each of these disorders. ${ }^{10,21,22}$

One component of the basement membrane that is not well understood is collagen VI (COL6). COL6 is a beaded filament-forming collagen that can be found in the basement membrane region of epithelial tissues (eg, intestine, testis, and skin), muscle, and extensively throughout the lung. ${ }^{23,24}$ Previous work has implied that the major function of COL6 is to connect the cells it surrounds with the matrix. ${ }^{25,26}$ COL6 can promote cell autonomous functions, including adhesion, migration, proliferation, survival, and differentiation in muscle, fibroblasts, and adipose tissue. ${ }^{26}$ Mutations in COL6 are known to cause a spectrum of muscular dystrophies (the collagen VI muscular dystrophies). ${ }^{27-30}$ Reduction or complete absence of COL6 in individuals with these muscular dystrophies is thought to cause impaired attachment of muscle cells to the surrounding matrix, resulting in apoptosis of the muscle cells. ${ }^{31}$ Respiratory insufficiency is a common characteristic of the collagen VI muscular dystrophies, often attributed to muscular weakness and contractures of the chest wall. ${ }^{32}$

Studies examining a primary role for COL6 in the lung are limited. COL6 is found throughout the human lung, predominantly in basement membrane regions; pulmonary epithelial cell spreading and wound-healing responses are enhanced on substrates containing COL6 in vitro. ${ }^{24}$ COL6 is the most abundant collagen in the mouse lung. ${ }^{16}$ On the basis of these observations, we tested the hypothesis that COL6 plays an important role in lung structure and function. We report herein that mice lacking COL6 have multiple molecular, cellular, pathologic, and physiological abnormalities in the lung.

\section{Materials and Methods}

\section{Mouse Breeding and Genotyping}

Col6al ${ }^{+-}$male and female mice were bred to produce Col6al $^{-1-}$ offspring. ${ }^{33}$ Homozygous Col6al ${ }^{-/-}$males and females were bred to produce Col6a1 ${ }^{-/-}$litters. Concurrently, and within the same housing facility, wild-type (WT) males and females were bred to produce wild-type controls. For genotyping, at 4 weeks of age, the tip of the tail was removed with a razor blade and placed into an Eppendorf tube for each animal. For each sample, $300 \mu \mathrm{L}$ of DirectPCR Lysis buffer (102-T; Viagen Biotech, Los Angeles, CA) was added, and tubes were incubated at $55^{\circ} \mathrm{C}$ overnight. The lysis mixture was then incubated at $85^{\circ} \mathrm{C}$ for 45 minutes, vortexed for 3 seconds, and incubated at room temperature for 15 minutes. For PCR, $2 \mu \mathrm{L}$ of DNA lysis mixture was added to a master mix containing $10 \mu \mathrm{L}$ GoTaq Green (M712; Promega, Madison, WI), $7 \mu \mathrm{L}$ UltraPure distilled water (10977-015; Invitrogen, Grand Island, NY), and $1 \mu \mathrm{L}$ of primer (WT Col6al forward, 5'-GCTGTGTTTAGCTGCCTGA-3'; WT Col6al reverse, 3'-CAGGTTGTCAATGAAGCGCT-5'; Col6al ${ }^{-\prime-}$ forward, 5'-CTGCTGGTGAGAATGGATGGTGT-3'; and Col6al ${ }^{-1-}$ reverse, $3^{\prime}-$ TGTGCCCAGTCATAGCCGAATAG-5 ${ }^{\prime}$ ). The tube was vortexed to mix, and the PCR was conducted using a BioRad T100 Thermal Cycler (BioRad, Hercules, CA), as follows: i) $94^{\circ} \mathrm{C}$ for 5 minutes, ii) $94^{\circ} \mathrm{C}$ for 1 minute, iii) $60.5^{\circ} \mathrm{C}$ for 1 minute, iv) $72^{\circ} \mathrm{C}$ for 2.5 minutes, v) repeat steps 2 through 4 $40 \times$, vi) $72^{\circ} \mathrm{C}$ for 10 minutes, and vii) $12^{\circ} \mathrm{C}$ indefinitely. For gel electrophoresis, $1 \mathrm{~g}$ of agarose (16500-100; Invitrogen, Carlsbad, CA) was mixed with $100 \mathrm{~mL}$ Tris-acetate-EDTA buffer (BP13324; Fisher, Hampton, NH) in a 500-mL Erlenmeyer flask. This mixture was heated by microwave for 90 seconds, mixed by swirling, and heated for an additional 30 seconds. Once heated, $6 \mathrm{~mL}$ of SYBR Safe DNA gel stain (S33102; Thermo, Waltham, MA) was added to the agarose solution. This mixture was poured into a BioRad wide mini-sub cell GT electrophoresis cell gel caster (1704468; BioRad), bubbles were removed using a pipette tip, and the gel was covered to protect from light for 20 minutes. Once cool, the comb was removed from the gel, and the gel was placed in the electrophoresis cell. Electrophoresis was performed for 45 minutes at $100 \mathrm{~V}$ in $1 \times$ Bolt transfer buffer (BT0006; Thermo). The gel was removed from the electrophoresis cell and imaged using a BioRad Gel Doc system (1708195EDU; BioRad) running Quantity One software version 4.6.7 (BioRad), build 012. Wild-type Col6al is visualized as a 1000 -bp band, whereas the knockout allele is a 594-bp band.

\section{Histology}

Mice were euthanized at 6 weeks of age by carbon dioxide narcosis and cervical dislocation. The thoracic cavity was opened, and the descending aorta was cut before perfusion of 
the lung vasculature with $1 \mathrm{~mL}$ cold phosphate-buffered saline (PBS) via the right ventricle. A suture was tied around the right main stem bronchus to prevent agarose inflation. The right lung lobes were removed, snap frozen in liquid nitrogen, and stored in $-80^{\circ} \mathrm{C}$ for RNA and protein extraction. The left lung was inflated to $24 \mathrm{mmHg}$ with $0.125 \%$ Low-Melt point agarose (16520-100; Invitrogen, Carlsbad, $\mathrm{CA})$ at $60^{\circ} \mathrm{C}$. The trachea was then clamped with a hemostat, removed from the thoracic cavity, and placed on ice for 10 minutes. Interpulmonary pressure was measured using a VWR Traceable Manometer (33500-082; VWR, Radnor, PA). Lungs were then fixed in $10 \%$ neutral-buffered formalin (5725; Thermo) at room temperature for 48 hours, washed in PBS for 20 minutes, and dehydrated in $30 \%, 50 \%$, and finally $70 \%$ ethanol for 20 minutes each at room temperature. Lungs remained in $70 \%$ ethanol at $4{ }^{\circ} \mathrm{C}$ before processing. The left lung was dissected and cut transversely in two locations, yielding three pieces of lung tissue. These three pieces were paraffin embedded and divided into sections along the transverse plane (5 $\mu \mathrm{m}$ thick).

\section{Immunofluorescence Staining}

Formalin-fixed, paraffin-embedded lung tissue sections were rehydrated in xylene $(2 \times), 1: 1$ xylene $/ 100 \%$ ethanol (89125-188; Koptec, King of Prussia, PA), $100 \%$ ethanol $(2 \times)$, 95\% ethanol (89125-180; Koptec), $70 \%$ ethanol, $50 \%$ ethanol, and tap water for 3 minutes each. Antigen retrieval was performed for 20 minutes in sodium citrate buffer made with $10 \mathrm{nmol} / \mathrm{L}$ sodium citrate (SX0445-1; EMD Millipore, Darmstadt, Germany) and $0.05 \%$ Tween 20 (23336-2500; Thermo) at $\mathrm{pH} 6.0$ in an Oster model 5711 steamer (Jarden, Rye, NY) at $95^{\circ} \mathrm{C}$, and submerged for 10 minutes in cool, running tap water. Slides were then washed in Tris-buffered saline (TBS) made with 6.05 $\mathrm{g}$ Tris (IB70144; IBI Scientific, Peosta, IA) and $8.76 \mathrm{~g}$ sodium chloride (42429-5000; Fisher), with $0.025 \%$ Triton X-100 (BP151-100; Fisher) and blocked in 10\% normal goat serum (ab7481; Abcam, Cambridge, MA) with 1\% bovine serum albumin (81-068-5; EMD Millipore) in TBS for 2 hours at room temperature. Primary antibodies for collagen VI (ab6588; Abcam), surfactant protein C (ab211326; Abcam), or normal rabbit IgG (sc2027; Santa Cruz Biotechnology, Dallas, TX) were diluted to $6 \mu \mathrm{g} / \mathrm{mL}$ in TBS with $1 \%$ bovine serum albumin and applied to slides, which were kept at $4{ }^{\circ} \mathrm{C}$ overnight. Slides were rinsed with TBS containing $0.025 \%$ Triton $\mathrm{X}-100$, and fluorescein isothiocyanate-conjugated fluorescent secondary antibody (a11034; Thermo) was diluted to $4 \mu \mathrm{g} / \mathrm{mL}$ and applied to slides for 1 hour at room temperature. Finally, slides were washed with TBS with $0.025 \%$ Triton X-100 and drained, and coverslips were mounted with Prolong Gold antifade mounting medium with DAPI (P36935; Thermo Fisher). Images were taken at $\times 40$ magnification using a Leica DFC365FX Camera mounted to a Leica DM5500B microscope and controlled by Leica Advanced Fluorescence version 3.1.0 imaging software (Leica, Wetzlar, Germany).

\section{Western Blot Analysis}

Frozen right superior lobes were placed in $300 \mu \mathrm{L}$ of radioimmunoprecipitation assay buffer containing protease/ phosphatase inhibitor, and homogenized using a Tissue Tearor homogenizer (985370; Biospec, Bartlesville, OK) for 1 minute. Protein was collected from cellular lysates after centrifugation at $10,000 \times g$ for 10 minutes. For Western blot analysis, isolated proteins (10 to $20 \mathrm{mg}$ ) were boiled for 10 minutes, resolved on SDS-PAGE, and transferred onto polyvinylidene difluoride membranes (1620175; BioRad). Membranes were blocked by incubation with $5 \%(w / v)$ nonfat dry milk (170-6404; BioRad) in Tris-buffered saline with Tween-20 $(10 \mathrm{mmol} / \mathrm{L}$ Tris, $\mathrm{pH} 8.0,150 \mathrm{mmol} / \mathrm{L}$ $\mathrm{NaCl}$, and $0.05 \%$ Tween-20) for 1 hour at room temperature. Membranes were incubated overnight with appropriate primary antibodies for collagen VI (ab6588; Abcam) or actin (I-19; sc-47778; Santa Cruz Biotechnology) diluted 1:1500. Finally, membranes were incubated for 1 hour with goat anti-rabbit $\mathrm{IgG}$-horseradish peroxidase antibody (sc2004; Santa Cruz Biotechnology) diluted 1:2000 and developed using a Supersignal West Femto ECL kit (34095; Thermo Scientific). The intensity of each band in the Western blot analysis was quantified by using ImageJ software version 1.49 (NIH, Bethesda, MD; http://imagej. nih.gov/ij).

\section{Lung Morphometry}

\section{$L_{m}$ Data}

Assessment of free space in the lung parenchyma was determined by measurement of mean linear intercept $\left(\mathrm{L}_{\mathrm{m}}\right)$. $\mathrm{L}_{\mathrm{m}}$ was measured by dividing the total length of a line drawn across the lung section by the number of times the line was intersected by tissue, as described. ${ }^{34}$ Briefly, for each mouse, six lung sections were imaged at $\times 20$ magnification. A grid with three parallel lines spaced at $60 \mu \mathrm{m}$ was overlaid onto the image. Mean linear intercept was defined by the average intercept distance between alveolar walls. Ten nonoverlapping fields for each section were examined.

\section{RAC Data}

Alveolarization was quantified by performing radial alveolar counts (RACs), as described. ${ }^{34,35}$ Terminal bronchioles were identified as bronchioles lined by columnar epithelium in one part of the wall. A line was drawn from the center of the terminal bronchiole perpendicular to the distal acinus (pleural surface). The number of alveoli bisected by the line was counted for each terminal bronchiole. At least three sections from various depths within the lung lobe, and a minimum of 30 respiratory bronchioles, were identified and used for RACs for each animal. 


\section{Pulmonary Function Testing}

Respiratory function testing was performed in 6-week-old Col6al $^{-1-}$ animals ( $N=5$ per group) and compared with similarly aged wild-type controls. Animals were anesthetized with i.p. ketamine/xylazine $(100 \mathrm{mg} / \mathrm{kg}$ and $100 \mathrm{mg} / \mathrm{kg}$, respectively) and were placed on a computer-controlled small animal ventilator (SCIREQ Inc., Montreal, ON, Canada) after tracheostomy with a blunt tip metal cannula. Ventilation was performed with a tidal volume of $10 \mathrm{~mL} / \mathrm{kg}, 150$ breaths/ minute, PEEP of $3 \mathrm{~cm} \mathrm{H} \mathrm{H}_{2} \mathrm{O}$, and $\mathrm{FIO}_{2}$ of $21 \%$. Once on the ventilator, pancuronium bromide $(2 \mathrm{mg} / \mathrm{kg}$ ) was given for neuromuscular blockade to ensure passive ventilation. Animals were placed on an external heating pad with temperature and heart rate monitored through the entire protocol. Baseline data and step-wise pressure-volume curves were obtained after at least 5 minutes of ventilation without evidence of spontaneous respiratory effort. Respiratory function data were obtained using the forced oscillation technique ${ }^{36}$ and analyzed using the constant phase model. ${ }^{37}$

\section{RNA Extraction}

To isolate total RNA, frozen tissue from right lung lobes was homogenized in $1 \mathrm{~mL}$ of TRIzol reagent (15596026; Invitrogen, Carlsbad, CA) with a Tissue Tearor homogenizer on ice, for 3 minutes. For each sample, $200 \mu \mathrm{L}$ of chloroform was added, and the sample was vortexed for 15 seconds. Samples were then centrifuged at $12,000 \times g$ for 15 minutes at $4{ }^{\circ} \mathrm{C}$. The top, aqueous layer was collected, and RNA was precipitated by adding $500 \mu \mathrm{L}$ isopropanol. Samples were incubated at room temperature for 15 minutes, and then centrifuged at $12,000 \times g$ for 10 minutes. The supernatant was removed, and the RNA pellet was washed with $500 \mu \mathrm{L}$ of $75 \%$ ethanol. Samples were mixed by vortexing for $10 \mathrm{sec}-$ onds, and centrifuged at $10,000 \times g$ for 5 minutes at $4^{\circ} \mathrm{C}$. The supernatant was removed, and the wash step was repeated once more. The ethanol supernatant was removed after the second wash, and samples were allowed to air dry for 10 minutes. The RNA was then dissolved in $100 \mu \mathrm{L}$ of RNAse/ DNAse-free water. Isolated RNA was repurified and rendered DNA free by an on-column DNase I treatment, according to the Agilent MiniPrep protocol (Agilent Technologies, Santa Clara, CA). RNA quantity was measured using UV absorbance, and quality was assessed using an Agilent 2100 Bioanalyzer (Agilent Technologies). Only samples with an RNA concentration $>100 \mathrm{ng} / \mu \mathrm{L}$ and an RNA integrity number $>8$ were used for RNA sequencing.

\section{RNA Sequencing}

In attempt to reduce the effects of biological variation, total RNA from two animals of the same genotype was pooled to generate each cDNA library. Each animal contributed to a single pool, with six total Col6al ${ }^{-/}$mice and six WT C57BL/6 mice contributing to three samples for each group.
Next, cDNA libraries $\left(n=3\right.$ for ColG $\mathrm{I}^{-/-} ; n=3$ for wild type) were generated, and high-throughput sequencing was completed by the University of Rochester (Rochester, NY) Genomics Research Center using an Illumina HiSeq2500v4 high-throughput DNA sequencer. Approximately 35 million reads were generated for each sample. Sequences were aligned to the mouse reference genome GRCm38.p5 using STAR version $2.5 .2 \mathrm{~b}^{38}$ implemented in R software version 3.4.1 (R Foundation for Statistical Computing, Vienna, Austria). Count estimation was performed using subread version 1.5.0p3, ${ }^{39}$ as implemented in R. Differential expression of genes was assessed using DESeq2 release $3.8^{40}$ with default parameters and lfcshrink to perform $\log 2$ transformation of the data (bioconductor.org, last accessed February 8 , 2018). These data are available for access via the Gene Expression Omnibus repository (https://www. ncbi.nlm.nih.gov/geo; accession number GSE135667).

\section{Cell-Type Enrichment Analysis}

Genes identified as differentially expressed were divided into two lists: significantly up-regulated and significantly down-regulated in the Col6al $1^{-1-}$ mouse. These lists were uploaded individually into the ToppFun Functional Enrichment tool (https://toppgene.cchmc.org/enrichment. $j s p$, last accessed January 17, 2019) and examined for enrichment using the Molecular Atlas of Lung Development Program Cincinnati Children's Hospital Medical Center Co-Expression Atlas to identify cell types with gene expression patterns that are significantly enriched in the input lists. Using the two input lists, cellular gene expression patterns that were increased or decreased in Col6a1 $^{-1-}$ mice were identified.

\section{Airway Number Quantification}

The dissection of the right lung lobe along the transverse plane, as described, produced three pieces of lung tissue, allowing for sectioning at three distinct depths. Images of whole transverse sections of lung lobes were taken at $\times 4$ magnification, at each of the three depths. The number of airways was counted in each image and averaged across all locations. This was repeated three times for each of nine WT and nine Col6al ${ }^{-1-}$ mouse lungs.

\section{Airway Epithelial Thickness Measurement}

Cross-sectional images of airways were obtained with a $20 \times$ objective from hematoxylin and eosin-stained WT and $\mathrm{Colbal}^{--}$lung tissue sections. The thickness of the epithelial cell layer was measured from the basal cell surface to the apical cell surface at four evenly spaced locations around the airway using ImageJ software. The average of these four measurements was taken. At least 10 airways were measured across each of six WT and seven Col6a1 ${ }^{-/-}$ mouse lungs. 


\section{Airway Epithelial Cell Density Measurement}

Cross-sectional images of airways were obtained with a $20 \times$ objective from hematoxylin and eosin-stained WT and Col6al $^{-/-}$lung tissue sections. The circumference or length of the cross-sectional segment of the airway was measured at the basal side of the epithelium using ImageJ software. The number of epithelial cells residing along the cross section of the airway was quantified by counting the number of nuclei using the ImageJ Cell Counter plugin.

\section{Measurement of Airway Epithelial Cell Nuclear Distance from Basement Membrane}

Cross-sectional images of airways were obtained with a $10 \times$ and $20 \times$ objective from hematoxylin and eosin-stained WT and Col6al ${ }^{-/-}$lung tissue sections. The average distance between the epithelial cell nuclei and the airway basement membrane was measured using ImageJ software and the Distance Between Lines plugin (http://imagej.1557.x6.nabble. com/Distance-Between-Lines-a-plugin-for-ImageJ-td3701802. html, last accessed September 1, 2019).

\section{Cell Culture}

16HBE cells, a large-T antigen transformed human bronchial epithelial cell line, were cultured under standard conditions at $37^{\circ} \mathrm{C}$ in a humidified incubator containing $5 \%$ $\mathrm{CO}_{2}{ }^{41}$ Cells were grown in Dulbecco's modified Eagle's medium (11965092; Gibco, Gaithersburg, MD) supplemented with $10 \%$ fetal bovine serum (10082147; Gibco), $1 \%$ penicillin/streptomycin (15140122; Gibco), 1\% nonessential amino acids (11140050; Gibco), sodium pyruvate (11360070; Gibco), and HEPES buffer (15630080; Gibco). Medium was replaced every 48 hours.

Primary pediatric human lung epithelial (PHLE) cells were isolated from distal lung tissue digests of donor-quality normal lung tissue from 1-day-old, 2-month-old, and 9-month-old donors, which were obtained by the human tissue core of the Molecular Atlas of Lung Development Program at the University of Rochester. ${ }^{42,43}$ Lung tissue was digested with a protease cocktail containing collagenase A (101033578001; Sigma-Aldrich, St. Louis, MO), dispase (354235; Corning, Corning, NY), elastase (LS002290; Worthington-Biochem, Lakewood, NJ), and DNAase (DN25; Sigma-Aldrich). Dissociated cells were washed twice in Dulbecco's PBS containing $1 \%$ penicillin-streptomycin (15140122; Gibco), $50 \mu \mathrm{g} /$ $\mathrm{mL}$ gentamicin, and $0.25 \mu \mathrm{g} / \mathrm{mL}$ amphotericin $\mathrm{B}$ and centrifuged with $800 \times g$ for 10 minutes. $^{42}$ These cells were then expanded in small airway basal medium containing bovine pituitary extract, hydrocortisone, human recombinant epidermal growth factor $(0.5 \mathrm{ng} / \mathrm{mL})$, epinephrine, insulin, triiodothyronine, transferrin, gentamicin, amphotericin B, retinoic acid, and bovine serum albumin (SAGM Bullet kit; CC-3118; Lonza, Basel, Switzerland) and supplemented with $1 \%$ fetal bovine serum. When $60 \%$ confluent, the cultures were gently trypsinized at room temperature with $2 \mathrm{~mL}$ of $0.0125 \%$ trypsin EDTA (25200056; Gibco) to remove fibroblasts. After depletion of fibroblasts, $95 \%$ of cells in these cultures stain for pan-cytokeratin. By real-time quantitative RT-PCR, PHLE cells express markers of airway epithelium. These expression data suggest that PHLE cells most closely resemble distal airway epithelium. ${ }^{43}$ All experiments were conducted using PHLE cells between passages 1 and 3 .

\section{Extracellular Matrix Coatings}

Tissue culture plates were coated with either COL6 from human placenta (009-001-108; Rockland, Limerick, PA), rat tail collagen I (COL1; 354236; BD Biosciences, San Jose, CA), or growth factor-depleted Matrigel (356231; Corning). Matrices were diluted in phenol red-free Dulbecco's modified Eagle's medium (31053028; Gibco) to a final concentration of $0.44 \mathrm{nmol} / \mathrm{L}$. In vitro assays were performed in 48 -well plates (containing $50 \mu \mathrm{L}$ of diluted matrix per well). After application of matrix solutions, plates were covered and kept at $37^{\circ} \mathrm{C}$ overnight and uncovered in the hood to dry for 1 hour before use.

\section{Steady-State Cell Density}

16HBE and PHLE cells were seeded at $5 \times 10^{5}$ cells per well in a 12-well plate coated with COL6, COL1, or Matrigel. Cells were fully confluent by 48 hours, at which point cells were stained for counting. PHLE cells were fixed in 10\% neutral-buffered formalin (5725; Thermo) for 10 minutes and stained with $300 \mathrm{nmol} / \mathrm{L}$ DAPI (D1306; Thermo) for 5 minutes. Cells were then washed with PBS, and mounted using Prolong Gold antifade mountant (P36934; Thermo). 16HBE cells were washed with PBS and stained with $1 \mathrm{~mL}$ of Cellmask Green stain (C37608; Thermo), diluted 1:1000 in PBS for 10 minutes. Cells were then washed with PBS and mounted using Prolong Gold antifade mountant. Cell density (cells per field) was quantified using the ImageJ Cell Counter plugin.

\section{Pathway Analysis}

Genes identified as differentially expressed were used for pathway analysis. Ingenuity Pathway Analysis software version 2.3 (Qiagen, Hilden, Germany) was applied in an effort to identify significantly overrepresented canonical pathways, defined by the Fisher exact test at $P<0.05$. Fold change between wild-type and Col6al $^{-/-}$samples was included in the analysis to identify pathways predicted to be up-regulated or down-regulated in the Col6a1 ${ }^{-/}$model.

\section{Cell-Signaling Inhibition}

Inhibitor experiments were performed in serum-containing medium. 16HBE or PHLE cells were seeded in matrix-coated 48 -well plates at 200,000 cells per well. At 24 
hours, cells were treated with small-molecule inhibitors against signaling proteins, Cdc42 [ZCL 278; $55 \mu \mathrm{mol} / \mathrm{L}$ in dimethyl sulfoxide (DMSO)], extracellular signal-regulated kinase (FR 180204; $3 \mu \mathrm{mol} / \mathrm{L}$ in DMSO), focal adhesion kinase (FAK; PF 573228; $40 \mathrm{nmol} / \mathrm{L}$ in DMSO), phosphatidylinositol 3-kinase (PI3K; LY294002; $10 \mu \mathrm{mol} / \mathrm{L}$ in DMSO), Rac (EHT 1864; $600 \mathrm{nmol} / \mathrm{L}$ in DMSO), and RhoA (CCG 1423; $3 \mu \mathrm{mol} / \mathrm{L}$ in DMSO). All inhibitors were obtained from Tocris Bioscience (Bristol, UK). Controls were treated with $3 \mu \mathrm{L}$ DMSO per well. Cell density was measured, as described, 24 hours after treatment (48 hours after seeding).

\section{Statistical Analysis}

Statistical analysis of RNA-sequencing data is described above. All other tests of significance were performed using a two-tailed, unpaired $t$-test implemented in Microsoft Excel 2010 (Microsoft, Redmond, WA).

\section{Results}

Collagen VI Localizes to Basement Membrane Regions of the Mouse Lung

To begin characterizing the effects of the $\mathrm{Col}_{\mathrm{a}} \mathrm{I}^{-/-}$deletion in the mouse lung, the location and abundance of COL6 in the lungs of mice carrying WT and Colbal ${ }^{-1-}$ alleles were examined. Immunofluorescence staining revealed that COL6 was widespread throughout the WT mouse lung, beneath the basal region of airway epithelium, in the subendothelial region in major vessels, and across the alveolar region (Figure 1A). No staining for COL6 was detected in the Col6a1 ${ }^{-/-}$lung. Western blot analysis of protein lysates from WT, heterozygous, and homozygous mouse lungs confirmed the absence of COL6 in the Col6a1 ${ }^{-1-}$ lungs, but equivalent levels in the WT and heterozygous mice (Figure 1, B and C).

\section{Altered Lung Physiology in Col6a1 ${ }^{-/-}$Mice}

Respiratory physiology was assessed to determine if the extent of alveolar structural changes in Col6al ${ }^{-/-}$lungs was sufficient to alter lung function. Several abnormalities were identified in pulmonary function in $\mathrm{Colbal}^{-1-}$ mice. Pressure-volume curves display increased lung volume for all tested pressures in Col6al ${ }^{-/-}$mice, relative to WT controls, confirmed by a $25.8 \%$ increase in quasi-static and respiratory system compliance $(P<0.01)$ (Figure $2, \mathrm{~A}-\mathrm{C}$ ). In Col6al ${ }^{-1-}$ mice, respiratory system resistance was reduced by $18.3 \% \quad(P<0.01)$, compared with WT (Figure 2D). Tissue damping, or energy dissipation in the alveoli, was reduced by $18.4 \%$ in $\mathrm{Col6al}^{-1-}$ lungs $(P<0.05)$ (Figure 2E). Tissue elastance, or the amount of the work required to fill and expand the lungs (stiffness),
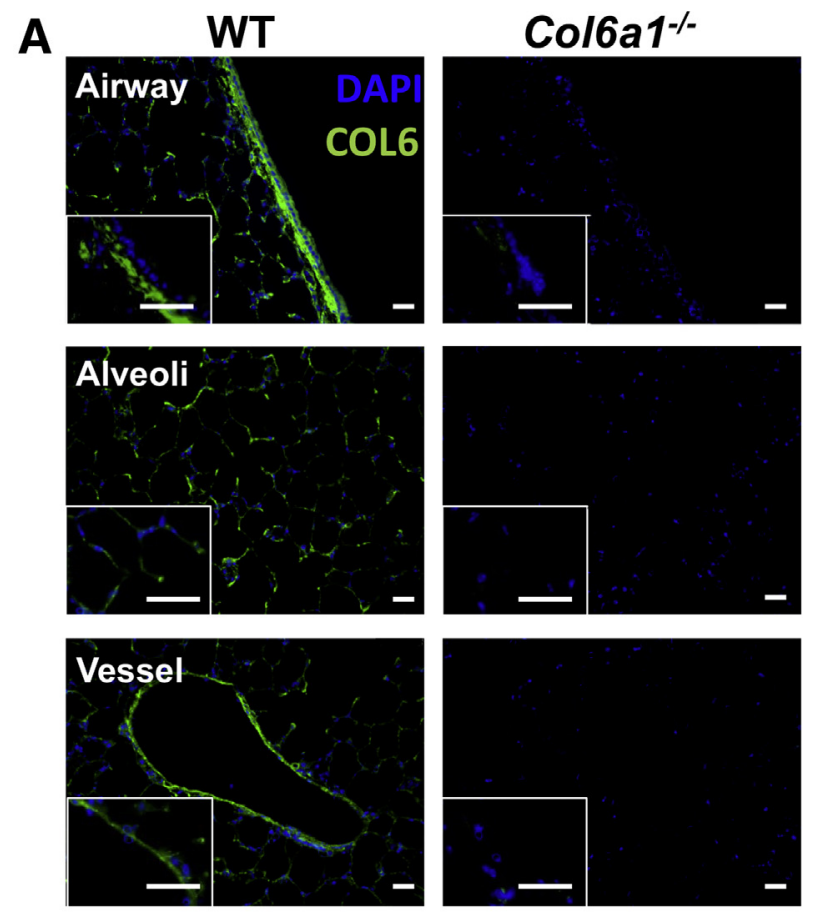

B

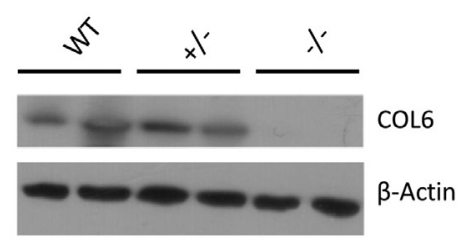

C

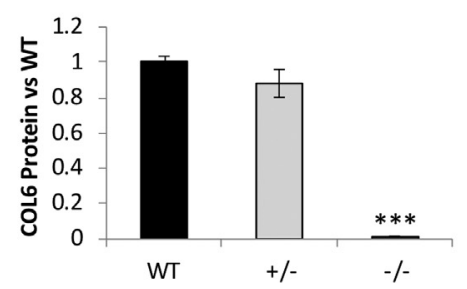

Figure 1 Location and abundance of COL6 in the mouse lung. A: Representative images of airway, alveolar, and blood vessel regions from wild-type (WT) and Col6a1-/- mice. Insets: IgG controls. B: Representative Western blot analysis of protein lysates from WT, Col6a1 ${ }^{+/-}$, and Col6a1 $1^{-/-}$ lungs. C: Quantification of band intensity from COL6 Western blot analysis relative to intensity of $\beta$-actin, expressed as the proportion to WT lungs. $n=6$ per group (B); $n=3$ per group (C). ${ }^{* * *} P<0.001$ versus WT. Scale bars $=25 \mu \mathrm{m}(\mathbf{A})$.

shows a trend toward significant difference in $\mathrm{Col}_{6 a 1^{-1}}$ mice, with a $19.2 \%$ reduction $(P=0.06)$ (Figure $2 \mathrm{~F})$.

\section{Loss of Collagen VI Results in Alveolar Simplification}

Histologic assessment of fixed, inflated lung sections from WT and Col6al ${ }^{-1-}$ mice revealed evidence for alveolar simplification (Figure 3A). To quantify the amount of free space in the lung parenchyma and the number of alveoli, $\mathrm{L}_{\mathrm{m}}$ and (RAC were calculated for Col6a1 ${ }^{-1-}$ and WT lungs. A $29.9 \%$ increase $(P<0.001)$ was found in $\mathrm{L}_{\mathrm{m}}$ (Figure 3B), 
A

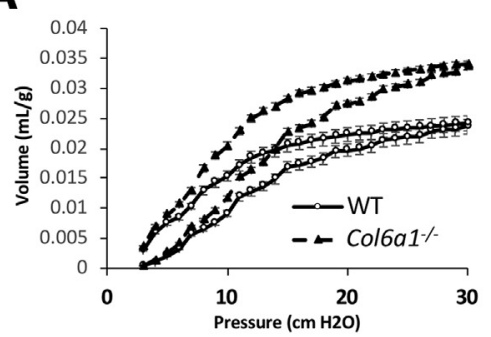

D

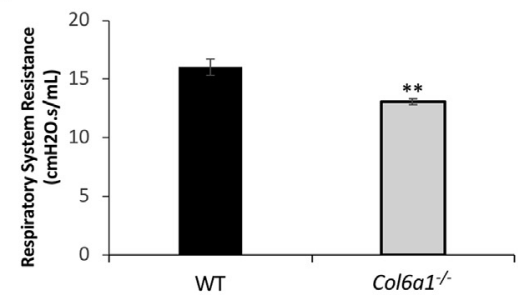

B

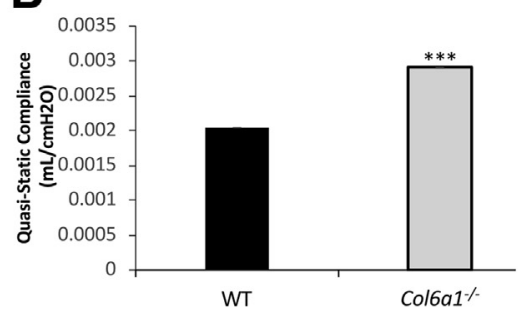

E

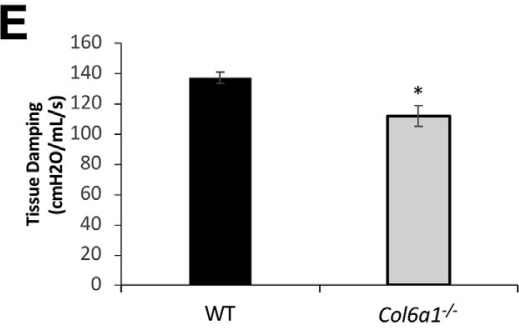

C
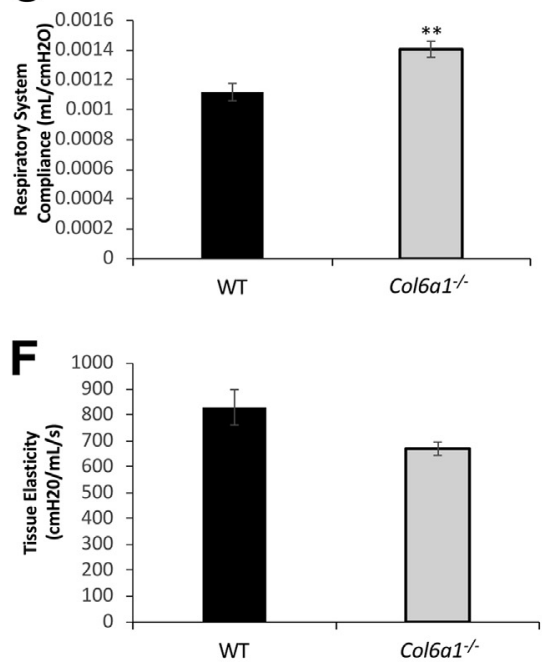

Figure 2 COL6 loss results in aberrant respiratory function. A: Pressure-volume curves for wild-type (WT) and Col6a1 ${ }^{-/-}$mice. B-F: Quasi-static compliance $(\mathbf{B})$, respiratory system compliance $(\mathbf{C})$, respiratory system resistance $(\mathbf{D})$, tissue damping $(\mathbf{E})$, and tissue elastance $(\mathbf{F})$ measures for WT and Col6a1 ${ }^{-/-}$mice. $n=5(\mathbf{A}-\mathbf{F}) .{ }^{*} P<0.05,{ }^{*} P<<0.01$, and ${ }^{*} * P<0.001$ versus WT.

and a $31.3 \%$ reduction $(P<0.01)$ was found in RAC (Figure 3C) in Col6al $^{-1-}$ relative to WT lungs.

\section{Reduced Alveolar Vasculature and ATII Cells in Col6a1 ${ }^{-/-}$Lungs}

To comprehensively define gene expression patterns, highthroughput sequencing (RNA sequencing) of RNA samples derived from lungs of WT and Colbal ${ }^{-/-}$mice was performed. A total of 742 genes were found to be significantly differentially expressed in the lung tissue of $\mathrm{Colbal}^{-/-}$mice after correction for multiple testing (false discovery rate $<$ 0.05): 467 were down-regulated, and 275 were upregulated (Figure 4A). Pathway analysis predicted that the most highly dysregulated pathways would be reduced in activity (Table 1). Ontological analysis of the 467 downregulated genes identified several cell types that appeared to be reduced in Col6a1 ${ }^{-/-}$lungs, including endothelial cells and alveolar epithelial type-II (ATII) cells (Supplemental Table S1). A total of 74 of the 467 downregulated genes were identified as endothelial cell markers (Figure 4B), and 30 genes were identified as ATII markers (Figure 4C).

Immunohistologic assessments were performed to validate these gene expression estimates for reduction in endothelial and alveolar epithelial cells. To assess alveolar vasculature, WT and Col6al ${ }^{-1-}$ lungs were stained with fluorescent-labeled isolectin B4 (lectin), which specifically binds to galactose found on the surface of endothelial cells. Lectin staining confirmed the reduction in alveolar vasculature, with total fluorescence intensity per field reduced by 29.4\% $(P<0.05)$ in Col6al ${ }^{-/}$lung tissue (Figure 5, A and C). It was also tested whether this loss in alveolar vasculature was simply proportional to the reduction in alveolar tissue. Lectin fluorescence intensity normalized to total cell number was also reduced in $\mathrm{Colbal}^{-1-}$ lung tissue by $20.9 \%(P<0.05)$ (Figure $5 \mathrm{E})$.

To assess ATII, WT and Col6al ${ }^{-1-}$ lungs were stained with antibodies against surfactant protein C. Surfactant protein $\mathrm{C}$ staining revealed a $35.6 \%$ reduction $(P<0.01)$ in ATII cell number per field in Col6al ${ }^{-1-}$ lungs relative to WT (Figure 5, B and D). It was tested whether this loss in ATII cells was simply proportional to the reduction in alveolar tissue and, therefore, total cell number. The percentage of surfactant protein $\mathrm{C}$-positive ATII cells was also reduced in Col6a1 ${ }^{-/-}$lung sections by $31.1 \%(P<0.001)$ when normalized to total cell number (Figure $5 \mathrm{~F}$ ).

\section{Loss of COL6 Leads to Altered Airway Morphology}

The presence of COL6 within and around the airway basement membrane region prompted further examination of the airway structure in Col6al ${ }^{-1-}$ mice. Qualitative assessment of hematoxylin and eosin staining from whole lung sections identifies an apparent increase in the number of airways in the Col6al ${ }^{-1-}$ lung (Figure 6A). The average airway number per transverse section reveals a $58.7 \%$ increase in Col6al ${ }^{-1-}$ mouse lungs $(P<0.001)$ (Figure 6B).

Because a direct role of COL6 has been demonstrated in regulating structure and function of airway epithelial cells, the mucosal layer of airways in $\mathrm{Colbal}^{-1-}$ mice was examined. ${ }^{23,44}$ The airway epithelium in Col6a1 ${ }^{-1-}$ lungs showed apparent thickening, with irregular positioning of the cells relative to the basement membrane (Figure 6C). Quantitative analysis showed that airway mucosal thickness was increased by $34.2 \%(P<0.001)$ in Col6al $^{-1-}$ lungs 


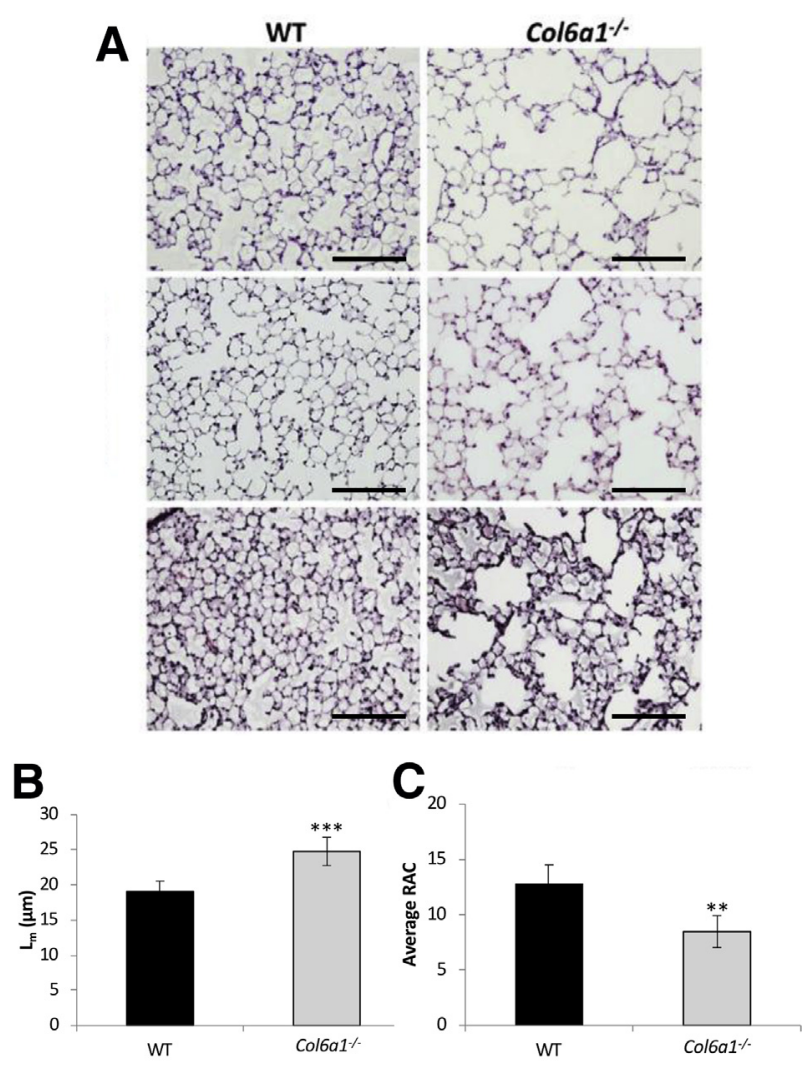

Figure 3 Alveolar structure in Col6 $6^{-/-}$mice. A: Representative images of the alveolar region from three wild-type (WT) and three Col6a1-/- mice. B and C: Quantification of alveolar mean linear intercept $\left(L_{m} ; \mathbf{B}\right)$ and radial alveolar count (RAC; $\mathrm{C}$ ) in WT and Col6a1 ${ }^{-1-}$ lungs. $n=6$ WT lungs (B and C) $; n=7$ Col6a1 ${ }^{-/-}$lungs (B and C). ${ }^{* *} P<0.01,{ }^{* *} P<0.001$ versus WT. Scale bar $=100 \mu \mathrm{m}(\mathbf{A})$.

relative to WT (Figure 6D). The epithelial cell density of the airways, defined as the number of nuclei per $100 \mu \mathrm{m}$ linear distance along the proximal-distal axis in the airway, was measured. Airway epithelial cell density was increased by 13.4\% $(P<0.001)$ in Col6al ${ }^{-1-}$ mice (Figure 6E). In addition, the average distance between airway epithelial cell nuclei and the airway basement membrane was increased by $83.7 \%(P<0.01)$ in Col6al $^{-1-}$ mice (Figure $\left.6 \mathrm{~F}\right)$.

\section{COL6 Regulates Lung Epithelial Cell Size}

Although the lung epithelial cells adhered and proliferated at the same rate on COL6 as other matrices, they appeared to reach confluence and show monolayer maturation (as evidenced by barrier function) more rapidly. This may be due to the effects of COL6 on airway epithelial cell size, similar to what was observed in the Col6al ${ }^{-1-}$ mouse. The effects of COL6 on airway epithelial cell size and density were directly tested using confluent monolayers of the human airway epithelial cell line 16HBE and the recently described primary cultures of human pediatric lung epithelial cells (PHLE). PHLE and 16HBE cells were plated at high density to ensure that they were confluent within 48 hours on uncoated plastic, Matrigel (a prototypical basement membrane that lacks COL6), COL6, or COL1. Cells were allowed to reach confluence, as determined by visualization and generation of transepithelial resistance $\left(>300 \Omega / \mathrm{cm}^{2}\right)$, fixed, and stained in situ. Membrane staining of 16HBE cells reveals an increase in cell size and reduction of cell density on COL6 relative to Matrigel or COL1 (Figure 7A). Cell number per field using 16HBE cells was reduced by $21.6 \%$ on COL6 relative to Matrigel $(P<0.05), 15.6 \%$ relative to COL1 $(P<0.05)$, and $28.0 \%$ compared with uncoated tissue culture plastic $(P<0.05)$ (Figure $7 \mathrm{~B})$. This was consistent with observations using primary PHLE cells. These cells reach confluence and form a resistant monolayer more rapidly on COL6 than on other matrices. Once at confluence, there are fewer cells per field, indicating reduced cell density on COL6 relative to confluent cells on other matrices (Supplemental Figure S1).

Integrin-mediated signaling through $\mathrm{PI} 3 \mathrm{~K}$ and $\mathrm{Cdc} 42$ is critical for COL6-mediated effects on lung epithelial cells. ${ }^{24}$ Analysis of the RNA-sequencing data from $\mathrm{Col} \mathrm{al}^{-/-}$ lungs identified 112 significantly enriched canonical pathways, many of which involved integrin-mediated signaling, including PI3K, Rho family GTPases, and paxillin (Supplemental Table S2 and Figure 7C). It was tested whether COL6 affects integrin signaling in confluent monolayers of lung epithelial cells by assaying levels of phosphorylated paxillin. 16HBE cells were grown to confluence on untreated plastic, Matrigel, COL6, or COL1, as described above. The levels of phosphorylated paxillin were significantly higher on COL6 than on other matrices tested (Figure 7, D and E).

The causal role of downstream signaling from paxillin in determining airway epithelial cell density differences on COL6 was studied using specific inhibitors for PI3K, Cdc42, RhoA, and Rac1. ${ }^{24}$ Inhibition of PI3K or Cdc42 resulted in significant increases $(P<0.05)$ in cell density ( $18.5 \%$ or $27.8 \%$, respectively) on COL6 (Figure $7 F$ ). Inhibition of downstream paxillin effectors Rac1 or RhoA had no effect. Inhibition of paxillin signaling-independent extracellular signal-regulated kinase and FAK did not significantly impact average cell size on COL6. Cell density on COL1 was significantly increased $(P<0.05)$ by $11.4 \%$ with inhibition of FAK and $17.5 \%$ with inhibition of Rac1, but not PI3K, Cdc42, extracellular signal-regulated kinase, or RhoA. Inhibition of PI3K, Cdc42, Rac1, RhoA, extracellular signal-regulated kinase, or FAK did not have a significant effect on average cell size for cells on Matrigel. These data support the integrin-paxillin-PI3K signaling specificity of the responses to COL6.

\section{Discussion}

Alterations in the organization and expression of many matrix components are known pathologic characteristics of 


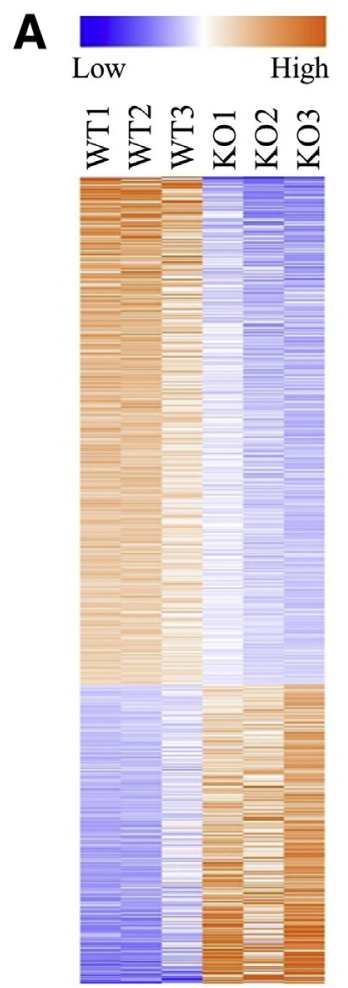

B Endothelial Cells

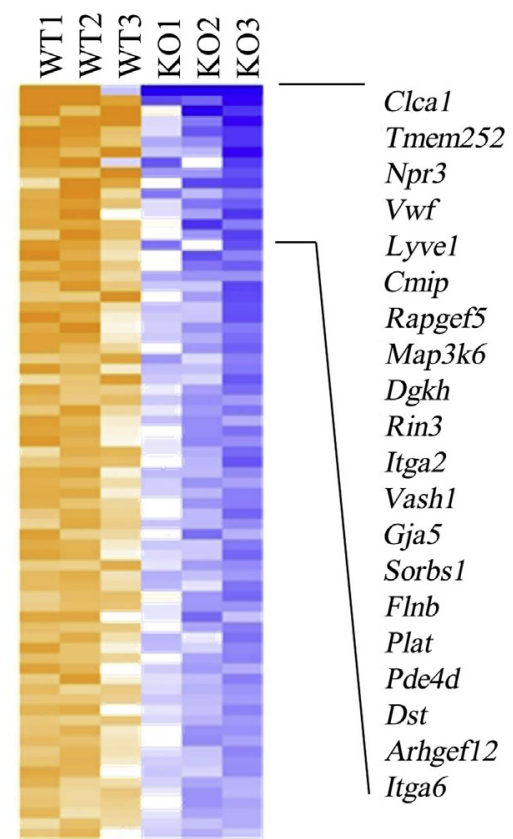

C ATII Cells

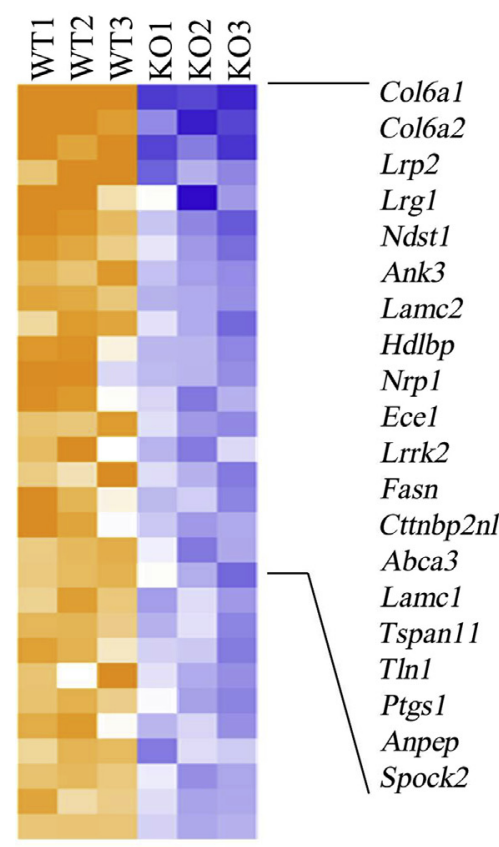

Figure 4 Markers of vasculature and alveolar epithelial type II (ATII) cells are reduced in Col6a1 ${ }^{-/-}$mouse lungs. A: Heat map displaying relative expression of all significantly differentially expressed genes between wild-type (WT) and Col6a1 ${ }^{-1}$ lung tissue. B and C: Heat maps show relative expression of genes associated with endothelial (B) and ATII (C) cells. Top 20 genes with largest fold change in Col6a1 ${ }^{-1-}$ mouse lungs are highlighted. K0, knockout.

diseases affecting lung structure and function, including chronic obstructive pulmonary disease, idiopathic pulmonary fibrosis, cancer, and BPD. ${ }^{10,45-47}$ COL6 is a basement membrane protein that can be found throughout many of the main structural components of lung tissue. ${ }^{23,24}$ Proteomic studies have identified COL6 as one of the most abundantly present proteins in the extracellular matrix of the mouse lung. ${ }^{16}$ There is a spectrum of muscular dystrophies known to be caused by mutations in COL6. Individuals with collagen VI muscular dystrophies often have impaired pulmonary function, and there is some evidence of changes in pulmonary structure in certain individuals. ${ }^{48,49}$ Limited studies have shown that COL6 may impact lung function and epithelial homeostasis. ${ }^{16,23}$ The effects of COL6 in the structure and organization of the mouse lung were further studied. The staining confirmed that COL6 is present throughout the alveoli, and beneath the airway epithelium and vascular endothelium, in the region of the basement membrane in WT mice (Figure 1). The localization of COL6, as well as its increasing expression throughout lung development, suggests that it may play a structural role in the lung, and that it may also influence activity of the epithelium. The Col6a1 ${ }^{-1-}$ mouse has no detectable COL6 in the lung and provides a suitable model for the study of the role of COL6 in lung structure.

The absence of COL6 results in multiple structural abnormalities in the mature mouse lung. There is significant simplification of the alveoli relative to wild-type lungs, identified by increased $\mathrm{L}_{\mathrm{m}}$ and reduced RAC (Figure 2). Reduced RAC and increased $\mathrm{L}_{\mathrm{m}}$ are potential indications of immaturity of the lung tissue at an age where the lung should have fully mature alveoli. ${ }^{50,51}$ The magnitude of the observed changes is consistent with previously reported values from lung diseases, like BPD and chronic obstructive pulmonary disease, and animal models of disease. ${ }^{52,53}$ Altered pressure-volume curves and increased compliance in Colbal ${ }^{-1-}$ mice (Figure 3) support the finding of

Table 1 Top 10 Most Dysregulated IPA Pathways in Col6a1 ${ }^{-/-}$ Lung Tissue by Z-Score

\begin{tabular}{lll}
\hline IPA pathway & Z-score & $-\log P$ value \\
\hline GP6 signaling pathway & 7.66 & -4.24 \\
Integrin signaling & 3.43 & -3.5 \\
NF- $K$ B activation by viruses & 4.94 & -3.46 \\
NF- $K$ B signaling & 3.39 & -3.21 \\
Tec kinase signaling & 1.47 & -3.16 \\
Paxillin signaling & 4.44 & -3 \\
Nitric oxide signaling in the & 2.14 & -3 \\
$\quad$ cardiovascular system & & \\
HGF signaling & 4.35 & -2.89 \\
IL-8 signaling & 1.78 & -2.89 \\
Leukocyte extravasation signaling & 2.71 & -2.84 \\
\hline
\end{tabular}

GP6, glycoprotein VI; HGF, hepatocyte growth factor; IPA, Ingenuity Pathway Analysis; Tec, tyrosine protein kinase Tec. 

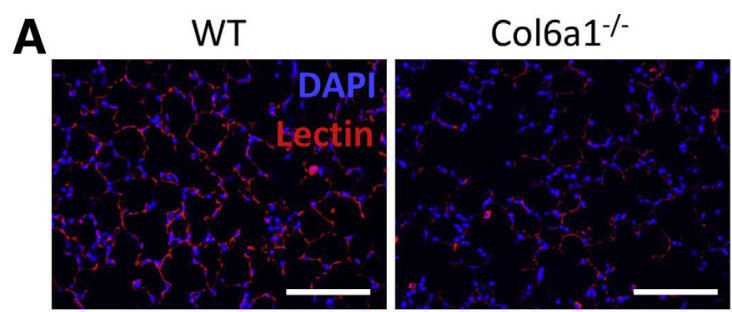

B
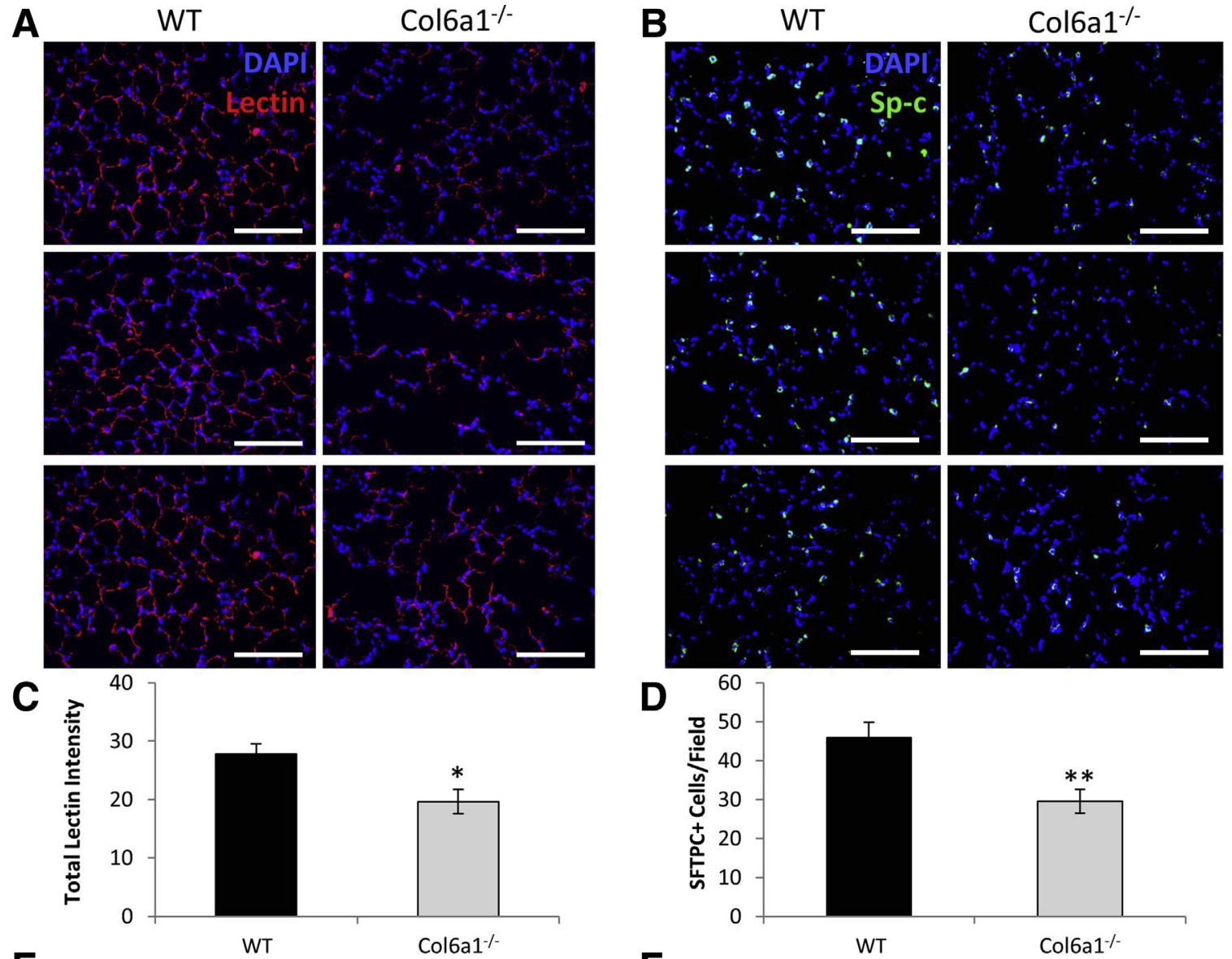

E
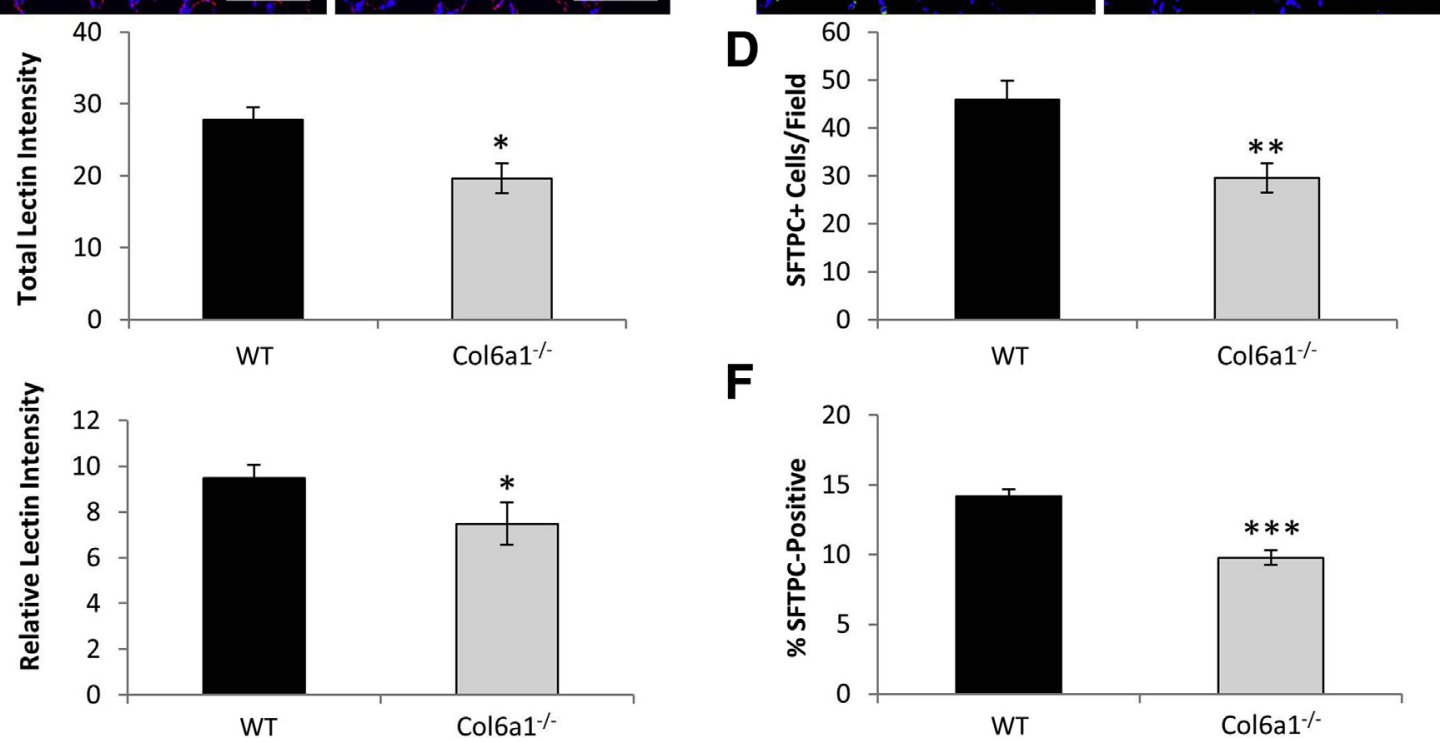

$\mathbf{F}$

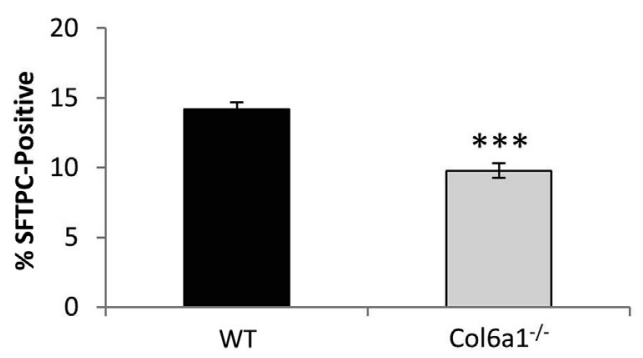

Figure 5 Alveolar vasculature and epithelial type II (ATII) cells are reduced in Col6a1 ${ }^{-/}$Lungs. A: Representative images of alveolar vasculature visualized by isolectin B4 staining (red) in wild-type (WT) and Col6a1 ${ }^{-1-}$ lung tissue. B and C: Quantification of vasculature by total lectin staining intensity (B) and lectin staining intensity normalized for cell number in WT and Col6a1 ${ }^{-/-}$lungs (C). D: Representative images of ATII cells visualized by surfactant protein C (SFTPC) staining (green) in WT and Col6a1 ${ }^{-/-}$lungs. E and F: Quantification of total SFTPC-positive cells per field (E) and the percentage of SFTPCpositive cells in WT and Col6a1 ${ }^{-/}$lungs $(\mathbf{F}) . n=6$ WT lungs $(\mathbf{C}$ and $\mathbf{F}) ; n=7$ Col6a1 ${ }^{-/-}$lungs $(\mathbf{C}$ and $\mathbf{F}) .{ }^{*} P<0.05,{ }^{* *} P<0.01$, and ${ }^{* * *} P<0.001$ versus WT. Scale bar $=100 \mu \mathrm{m}(\mathbf{A}$ and $\mathbf{B})$.

simplified parenchymal structure and obstructive lung disease, hallmark pathologic and functional findings in chronic and developmental lung diseases, including BPD. ${ }^{54}$ These structural abnormalities could result from a developmental defect or from a destructive process that occurs after a normal developmental process. We believe that this is more likely to be a result of a developmental abnormality than a destructive process. Destructive processes, like those observed in emphysema and chronic obstructive pulmonary disease, often are accompanied by increased inflammation and shortened lifespan in mouse models. However,
Col6al ${ }^{-/-}$mice do not show signs of increased inflammation, and appear to have a normal lifespan relative to wildtype mice, indicating that the condition in these mice may not be progressive and degenerative, but may be more likely a result of developmental defects. ${ }^{5,56}$ It is possible that COL6 plays a role in chronic lung disease due to prematurity, as longitudinal cohort studies have shown early evidence of obstructive lung disease persisting into adolescence and young adulthood. ${ }^{57,58}$

Genes with reduced expression in Col6al ${ }^{-1-}$ lungs are significantly enriched with markers of endothelial cells, B 

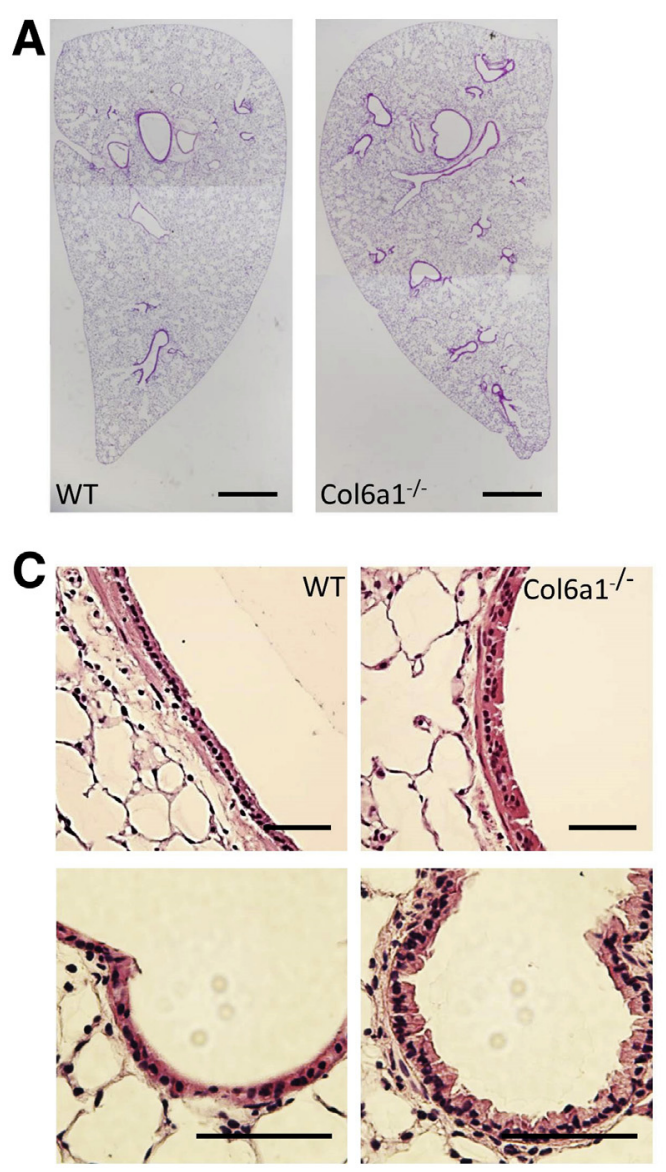

B

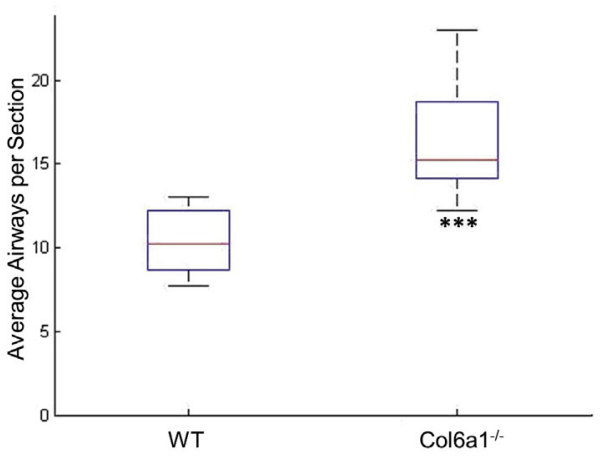

D

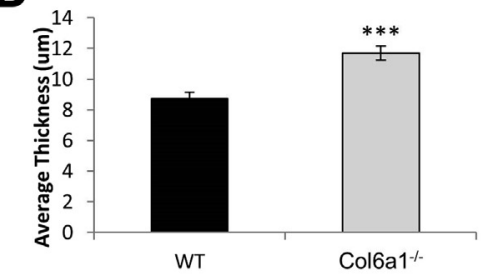

$F$

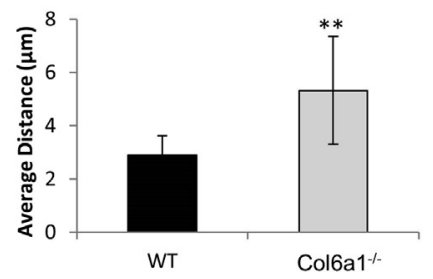

$\mathbf{E}$

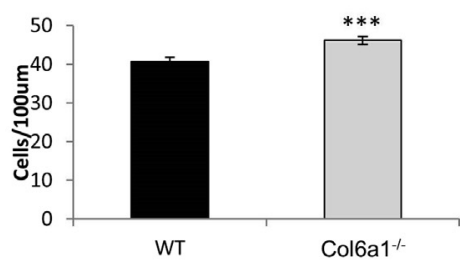

Figure 6 Airway structure and morphology is altered in the absence of COL6. A: Representative images of whole transverse sections of the left lung from wild-type (WT) and Col6a1 ${ }^{-1-}$ mouse lungs. B: Quantification of average airway number per section in WT and Col6a1 $1^{-/}$mice. C: Representative images of airways from two different WT and Col6a1 ${ }^{-/-}$mouse lungs. D-F: Quantification of airway epithelial cell density (nuclei/100 $\mu$ m; D), airway mucosal thickness (E), and average distance between airway epithelial cell nuclei and basement membrane (F) in WT and Col6a1 ${ }^{-1-}$ mice. $n=9$ WT and Col6a1 ${ }^{-/-}$mice (B); $n=6$ WT mice $(\mathbf{D}-\mathbf{F}) ; n=7$ Col6a1 ${ }^{-/-}$mice $(\mathbf{D}-\mathbf{F}) .{ }^{* *} P<0.01,{ }^{* *} P<0.001$ versus WT. Scale bars: $1 \mathrm{~mm}(\mathbf{A}) ; 100 \mu \mathrm{m}$ (C).

cells, and ATII cells (Figure 4). The vasculature and ATII cells were studied because of their well-known roles in lung development and structural organization. Lectin staining identifies a reduction in the intensity of vascular endothelial staining in Col6al $1^{-/}$lungs. However, because there was a reduction in the amount of tissue, the intensity was then normalized to nuclear number, revealing a reduction in staining intensity per nuclei. This is indicative of a reduction in vasculature that may not be completely explained by the simplification of the parenchyma (Figure 5, A-C). In addition, there was a reduction in the percentage of surfactant protein $\mathrm{C}$-positive ATII cells (Figure 5, D-F). Reduced vasculature and ATII cells are characteristics of developmental abnormalities associated with BPD and animal models of BPD. ${ }^{59,60}$ ATII cells are known to produce critical mitogens during lung development, including vascular endothelial growth factor (VEGF). ${ }^{61}$ It has also been shown that VEGF is necessary for the development of proper alveolar structure. ${ }^{61-63}$ Expression of one member of the VEGF family of ligands, VEGFc, is significantly reduced in Col6al ${ }^{-1-}$ mouse lungs by $t$-test (fold change $=0.86 ; P<0.05$ ) (data not shown). It has been shown that this ligand is expressed in ATII cells and is involved in the expansion of the vascular and lymphatic systems. ${ }^{64,65}$ The reduction in ATII cells, therefore, provides a potential mechanism for the reduction of vasculature and alveolar simplification observed in the Col6a1 ${ }^{-/-}$lung.

Previous reports of COL6 in association with the developing airway, and its abundance in the airway basement membrane, prompted the examination of the airway epithelium in Col6al ${ }^{-/-}$mice. ${ }^{24,44}$ Developmentally, COL6 is found surrounding the branching airways, along with collagen I, collagen III, and several other noncollagen matrix components. It is postulated that these collagens are responsible for the stabilization of the airways and that their absence at the terminal surface of the airway may promote growth at that location. ${ }^{44,66}$ Consistent with this work, the increase in airway number identified in $\mathrm{Col}_{6 a 1}{ }^{-/-}$mice implies that the presence of COL6 may be critical to proper branching morphogenesis (Figure 6, A and B). Characterization of a murine model of annexin A2 loss of function, 

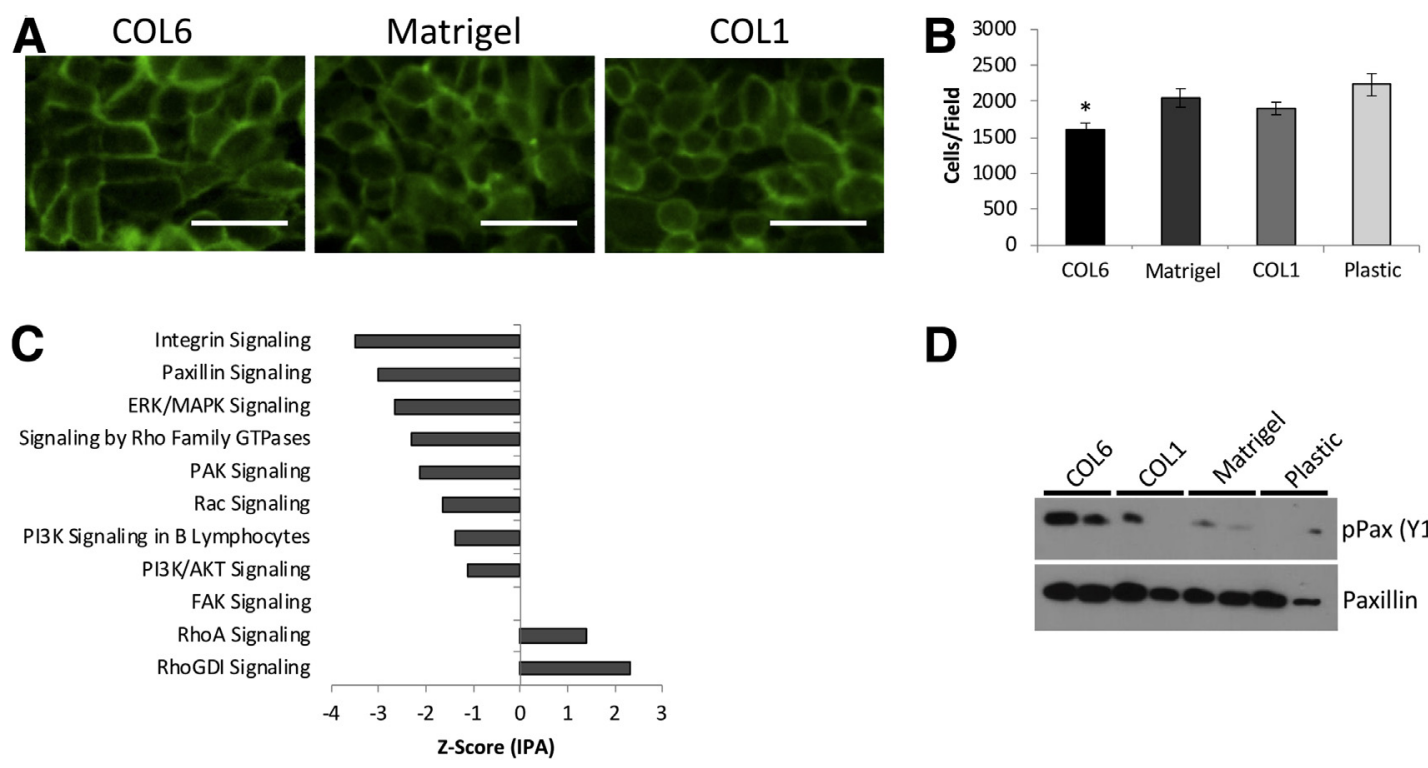

D
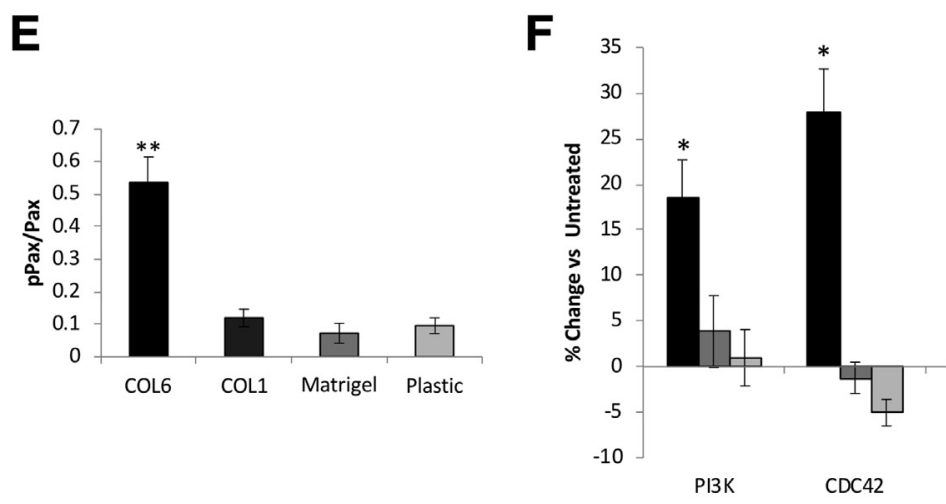

Figure 7 COL6 regulates lung epithelial cell monolayer density. A: Representative images of plasma membrane staining of fully confluent monolayers of $16 \mathrm{HBE}$ cells on COL6, Matrigel, and COL1 matrix coatings. B: Quantification of cell density (cells/field) from A. C: Z-scores representing predicted activity of elected canonical pathways significantly associated with differentially expressed genes in Col6a1 ${ }^{-1}$ mouse lungs. D and E: Western blot analysis (D) and quantification of phosphorylated paxillin (pPax) relative to total paxillin (E). F: Quantification of the percentage change in cell density (cells/field) in cells treated with inhibitors of phosphatidylinositol 3-kinase (PI3K), Cdc42, RhoA, focal adhesion kinase (FAK), Rac1, and extracellular signal-regulated kinase (ERK) at steady state relative to untreated cells on COL6, COL1, and Matrigel. Data are expressed as means \pm SD (B). $n=6(\mathbf{B}$ and $\mathbf{F}) ; n=3(\mathbf{E}) .{ }^{*} P<0.05, * * P<0.01$ versus Matrigel. Scale bar $=25 \mu \mathrm{m}(\mathbf{A})$. MAPK, mitogen-activated protein kinase; PAK, p21 activated kinase; RhoGDI, rho GDP dissociation inhibitor.

which is unable to transport and secrete functional COL6, although not preventing its production, shows altered lung physiology, increased epithelial apoptosis, and irregular airway morphology. ${ }^{23}$ Although this model may affect the deposition of additional proteins, it provides some indication that COL6 may be important to lung structure and function.

In addition to effects on global airway structure, the airway epithelium is significantly thickened, and the epithelial cell density (cells/distance) is significantly higher in Col6a1 ${ }^{-1-}$ airways (Figure 6, C-E). It is possible that the observed alteration in cell density is due to changes in the composition of cell types (with different sizes and characteristics) in the airway. For example, in the alveolus, an ATII cell is significantly smaller than an ATI cell. An increase in the proportion of ATII cells would significantly increase the cell density of the alveolar epithelium. However, in vitro studies on airway epithelial cells argue that increased cell density in the absence of COL6 may be due to alterations in spreading and signaling from the matrix. COL6 promotes airway epithelial cell spreading and wound healing in vitro, but does not impact adhesion or proliferation. ${ }^{24}$ It was confirmed that the absence of COL6 causes higher density of airway epithelial cells using two models of airway epithelium (Figure 7, A and B). Cell density has known effects on the ability of the pulmonary epithelial cells to migrate during multiple processes, including development and injury repair. Additional work has shown that increased airway epithelial cell density can inhibit or impair the collective migration of the epithelial monolayer. ${ }^{67,68}$ Epithelial cell function, including migration, spreading, and proliferation, is critical to processes, including alveolar septation, microvascular development, and airway branching morphogenesis. Disruption of the ability of the epithelium to perform these functions can be severely detrimental to 
the structural development and organization of the lung. ${ }^{9,69}$ The loss of COL6 results in a state that resembles an immature lung. It is possible that alterations in COL6 may contribute to the development or severity of chronic lung diseases, like BPD, by delaying lung development. It is also possible that loss or dysfunction of COL6 may increase susceptibility to mechanical injury, by increasing lung compliance and allowing for chronic overinflation of the lung tissue.

Pathway analysis of genes with significant differential expression in Col6a1 ${ }^{-1-}$ lung tissue identifies multiple pathways associated with this dysregulated gene signature, including integrin signaling, PI3K signaling in B lymphocytes, actin cytoskeleton signaling, and paxillin signaling (Figure 7C). COL6 enhances pulmonary epithelial spreading and wound healing via PI3K and Cdc42 downstream of integrin signaling, but likely independent of FAK. ${ }^{24}$ We examined whether similar pathways may be promoting the low cell density at steady state on COL6, and found that inhibition of PI3K and Cdc42 causes a significant and specific increase in cell density on COL6, nearly to the density observed in cells on Matrigel. Interestingly, inhibition of FAK and Rac1 results in increased steady-state cell density on COL1, indicating a potentially different mechanism of cell spreading and monolayer maintenance in cells on COL1 relative to COL6. Furthermore, none of the tested inhibitors affected the cell density on Matrigel. This may be due to Matrigel being a mixture of multiple ECM components known to work through multiple additional receptors and redundant mechanisms, and the fact that inhibition of a single molecule may not be enough to alter cell density. ${ }^{70,71}$ The $\mathrm{PI} 3 \mathrm{~K} / \mathrm{Cdc} 42$ signaling pathway may be responsible for the reduced steady-state cell density on COL6 (Figure 7F). In addition, the activation status of paxillin in confluent 16HBE monolayers on coatings of COL6, Matrigel, COL1, or tissue culture plastic was examined. A significant increase in paxillin activation was observed in cells on COL6 (Figure 7, D and E). Paxillin is found in focal adhesions and has been identified as an activator of several molecules downstream of integrin, including PI3K. ${ }^{72,73}$ Therefore, paxillin may be playing a role in the PI3K/ Cdc42 signaling mechanism downstream of COL6 in the pulmonary epithelium.

The loss of Col6al may result in aberrant accumulation of other collagen VI protein chains or compensatory alterations in expression of these genes. Increased levels of collagen VI protein chains could result in the formation of other COL6 protein complexes, leading to potential gainof-function activities, or stress the cell to the point of apoptosis. This mechanism could be contributing to the increased rate of apoptosis observed in the airway epithelium of the annexin A2 knockout mouse described by Dassah et al. ${ }^{23}$ RNA-sequencing data from the lung tissue of WT and Col6al ${ }^{-1-}$ mice revealed a significant reduction in Col6al and Col6a2 mRNA expression, but no significant differences were observed in the expression of Col6a3, Col6a4, Col6a5, or Col6a6. In addition, the use of a polyclonal antibody against COL6 displayed some cross-reactivity with other COL6 protein chains or structures. However, no signal was detected when staining of lung tissue from Col6al ${ }^{-/-}$mice with this antiCOL6 antibody. Despite these results, additional studies of compensatory mechanisms or gain of function resulting from the loss of Col6al would benefit the interpretation of the observed alterations in lung tissue in this model.

There are limitations within these studies. First, the lung phenotypes were examined at 6 weeks of age, a time where the lungs should be fully mature. Although the structural abnormalities are likely to be developmental, the full ontogeny of the structural changes in Col6al ${ }^{-/-}$lungs has not been defined. In addition, further study of aged mice would provide information on whether there is a progressive component to these alterations of lung structure. These analyses may also identify when the alterations in vasculature and ATII cells appear, and what roles they may play. Another potential limitation is that these mice also display a mild form of myopathy, which impacts the diaphragm. It is possible that altered respiratory musculature may influence lung development and pulmonary function, contributing to some of the alterations we observe. However, the cellular and molecular changes observed in the Col6al ${ }^{-1-}$ mouse lung, as well as studies of the effects of COL6 on pulmonary epithelial cell function, suggest that the effects of COL6 loss on lung structure and function likely involve the lung tissue itself. However, further investigation of the pulmonary musculature is necessary to determine whether there are more subtle alterations that may be involved in the observed phenotypes. Finally, our studies identify paxillin as a possible mediator of response to COL6. However, there are no small-molecule inhibitors of paxillin. Therefore, inhibitors of multiple signaling proteins known to be downstream of paxillin were used. Additional studies examining the direct effects of paxillin in response to COL6, and its effects on pulmonary epithelial cell function, are necessary.

In summary, the loss of COL6 results in significant alteration to lung structure in mice. Reduced expression of COL6 may lead to developmental abnormalities or failure to maintain homeostasis and may contribute to chronic lung disease. Additional studies on the role of COL6 throughout developmental processes and its potential involvement in disease would be beneficial to the field of lung biology.

\section{Acknowledgments}

We thank Dr. Siva K. Solletti, Dr. Ravi Misra, Christopher S. Slaunwhite, Dr. Thomas Thatcher, and Wade Narrow for technical advice and experimental support; Dirk Bohmann, 
Helene R. McMurray, Douglas S. Portman, and Gloria S. Pryhuber for many helpful conversations and advice; Eric Hernady (University of Rochester Environmental Health Sciences Center Histology Core) for help in processing specimens for histologic assessment; and the Genomics Research Center (University of Rochester Medical Center) for facilitating the transcriptome analyses described in this study.

\section{Author Contributions}

J.A.M. and T.J.M. designed the studies, analyzed the data, and wrote the article; J.A.M., Y.R., C.S.A., K.D., A.M.D., and J.H. performed the experiments and collected data; S.B., Y.R., Q.W., C.S.A., A.M.D., J.H., A.A., and P.B. contributed reagents and analytical tools; J.A.M. and T.J.M. are the guarantors of this work and, as such, had full access to all the data in the study and take responsibility for the integrity of the data and the accuracy of the data analysis.

\section{Supplemental Data}

Supplemental material for this article can be found at http://doi.org/10.1016/j.ajpath.2019.10.014.

\section{References}

1. Booth AJ, Hadley R, Cornett AM, Dreffs AA, Matthes SA, Tsui JL, Weiss K, Horowitz JC, Fiore VF, Barker TH, Moore BB, Martinez FJ, Niklason LE, White ES: Acellular normal and fibrotic human lung matrices as a culture system for in vitro investigation. Am J Respir Crit Care Med 2012, 186:866-876

2. Petersen TH, Calle EA, Colehour MB, Niklason LE: Matrix composition and mechanics of decellularized lung scaffolds. Cells Tissues Organs 2012, 195:222-231

3. White ES: Lung extracellular matrix and fibroblast function. Ann Am Thorac Soc 2015, 12 Suppl 1:S30-S33

4. Kim SH, Turnbull J, Guimond S: Extracellular matrix and cell signalling: the dynamic cooperation of integrin, proteoglycan and growth factor receptor. J Endocrinol 2011, 209:139-151

5. Frantz C, Stewart KM, Weaver VM: The extracellular matrix at a glance. J Cell Sci 2010, 123:4195

6. Lu P, Takai K, Weaver VM, Werb Z: Extracellular matrix degradation and remodeling in development and disease. Cold Spring Harb Perspect Biol 2011, 3:a005058

7. Li J, Wang Z, Chu Q, Jiang K, Li J, Tang N: The strength of mechanical forces determines the differentiation of alveolar epithelial cells. Dev Cell 2018, 44:297-312.e5

8. Xu J, Liu M, Post M: Differential regulation of extracellular matrix molecules by mechanical strain of fetal lung cells. Am J Physiol 1999, 276:L728-L735

9. McGowan SE: Extracellular-matrix and the regulation of lung development and repair. FASEB J 1992, 6:2895-2904

10. Mižíková I, Morty RE: The extracellular matrix in bronchopulmonary dysplasia: target and source. Front Med 2015, 2:91

11. Vlahovic G, Russell ML, Mercer RR, Crapo JD: Cellular and connective tissue changes in alveolar septal walls in emphysema. Am J Respir Crit Care Med 1999, 160:2086-2092

12. Tuder RM, Yoshida T, Arap W, Pasqualini R, Petrache I: State of the art: cellular and molecular mechanisms of alveolar destruction in emphysema: an evolutionary perspective. Proc Am Thorac Soc 2006, 3:503-510

13. Nguyen NM, Kelley DG, Schlueter JA, Meyer MJ, Senior RM, Miner JH: Epithelial laminin alpha5 is necessary for distal epithelial cell maturation, VEGF production, and alveolization in the developing murine lung. Dev Biol 2005, 282:111-125

14. Shannon JM, Nielsen LD, Gebb SA, Randell SH: Mesenchyme specifies epithelial differentiation in reciprocal recombinants of embryonic lung and trachea. Dev Dyn 1998, 212:482-494

15. Zhou Y, Horowitz JC, Naba A, Ambalavanan N, Atabai K, Balestrini J, Bitterman PB, Corley RA, Ding B-S, Engler AJ, Hansen KC, Hagood JS, Kheradmand F, Lin QS, Neptune E, Niklason L, Ortiz LA, Parks WC, Tschumperlin DJ, White ES, Chapman HA, Thannickal VJ: Extracellular matrix in lung development, homeostasis and disease. Matrix Biol 2018, 73:77-104

16. Burgstaller G, Oehrle B, Gerckens M, White ES, Schiller HB, Eickelberg O: The instructive extracellular matrix of the lung: basic composition and alterations in chronic lung disease. Eur Respir J 2017, 50:1601805

17. LeBleu VS, Macdonald B, Kalluri R: Structure and function of basement membranes. Exp Biol Med (Maywood, NJ) 2007, 232: $1121-1129$

18. Kahsai TZ, Enders GC, Gunwar S, Brunmark C, Wieslander J, Kalluri R, Zhou J, Noelken ME, Hudson BG: Seminiferous tubule basement membrane: composition and organization of type IV collagen chains, and the linkage of alpha3(IV) and alpha5(IV) chains. J Biol Chem 1997, 272:17023-17032

19. Watanabe K, Senju S, Toyoshima H, Yoshida M: Thickness of the basement membrane of bronchial epithelial cells in lung diseases as determined by transbronchial biopsy. Respir Med 1997, 91: 406-410

20. Weibel ER: On the tricks alveolar epithelial cells play to make a good lung. Am J Respir Crit Care Med 2015, 191:504-513

21. Strieter RM: What differentiates normal lung repair and fibrosis? inflammation, resolution of repair, and fibrosis. Proc Am Thorac Soc 2008, 5:305-310

22. Liesker JJ, Ten Hacken NH, Zeinstra-Smith M, Rutgers SR, Postma DS, Timens W: Reticular basement membrane in asthma and COPD: similar thickness, yet different composition. Int J Chron Obstruct Pulmon Dis 2009, 4:127-135

23. Dassah M, Almeida D, Hahn R, Bonaldo P, Worgall S, Hajjar KA: Annexin A2 mediates secretion of collagen VI, pulmonary elasticity and apoptosis of bronchial epithelial cells. J Cell Sci 2014, 127:828-844

24. Mereness JA, Bhattacharya S, Wang Q, Ren Y, Pryhuber GS, Mariani TJ: Type VI collagen promotes lung epithelial cell spreading and wound-closure. PLoS One 2018, 13:e0209095

25. Kuo H-J, Maslen CL, Keene DR, Glanville RW: Type VI collagen anchors endothelial basement membranes by interacting with type IV collagen. J Biol Chem 1997, 272:26522-26529

26. Cescon M, Gattazzo F, Chen P, Bonaldo P: Collagen VI at a glance. J Cell Sci 2015, 128:3525

27. Jobsis GJ, Boers JM, Barth PG, de Visser M: Bethlem myopathy: a slowly progressive congenital muscular dystrophy with contractures. Brain 1999, 122:649-655

28. Fernandez M, Pacheco M, Garaizar C, Prats JM: [Congenital atonicsclerotic muscular dystrophy (Ullrich disease)]. Spanish. Neurologia 1991, 6:259-262

29. Bönnemann CG: The collagen VI-related myopathies: muscle meets its matrix. Nat Rev Neurol 2011, 7:379-390

30. Jobsis GJ, Keizers H, Vreijling JP, de Visser M, Speer MC, Wolterman RA, Baas F, Bolhuis PA: Type VI collagen mutations in Bethlem myopathy, an autosomal dominant myopathy with contractures. Nat Genet 1996, 14:113-115

31. Kawahara G, Okada M, Morone N, Ibarra CA, Nonaka I, Noguchi S, Hayashi YK, Nishino I: Reduced cell anchorage may cause sarcolemma-specific collagen VI deficiency in Ullrich disease. Neurology 2007, 69:1043-1049 
32. Nadeau A, Kinali M, Main M, Jimenez-Mallebrera C, Aloysius A, Clement E, North B, Manzur AY, Robb SA, Mercuri E, Muntoni F: Natural history of Ullrich congenital muscular dystrophy. Neurology 2009, 73:25-31

33. Bonaldo P, Braghetta P, Zanetti M, Piccolo S, Volpin D, Bressan GM: Collagen VI deficiency induces early onset myopathy in the mouse: an animal model for Bethlem myopathy. Hum Mol Genet 1998, 7:2135-2140

34. Cooney TP, Thurlbeck WM: The radial alveolar count method of Emery and Mithal: a reappraisal 2-intrauterine and early postnatal lung growth. Thorax 1982, 37:580-583

35. Emery JL, Mithal A: The number of alveoli in the terminal respiratory unit of man during late intrauterine life and childhood. Arch Dis Child 1960, 35:544-547

36. Shalaby KH, Gold LG, Schuessler TF, Martin JG, Robichaud A: Combined forced oscillation and forced expiration measurements in mice for the assessment of airway hyperresponsiveness. Respir Res 2010, 11:82

37. Hantos Z, Daroczy B, Suki B, Nagy S, Fredberg JJ: Input impedance and peripheral inhomogeneity of dog lungs. J Appl Physiol (1985) 1992, 72:168-178

38. Dobin A, Davis CA, Schlesinger F, Drenkow J, Zaleski C, Jha S, Batut P, Chaisson M, Gingeras TR: STAR: ultrafast universal RNAseq aligner. Bioinformatics 2013, 29:15-21

39. Liao Y, Smyth GK, Shi W: The R package Rsubread is easier, faster, cheaper and better for alignment and quantification of RNA sequencing reads. Nucleic Acids Res 2019, 47:e47

40. Love MI, Huber W, Anders S: Moderated estimation of fold change and dispersion for RNA-seq data with DESeq2. Genome Biol 2014, 15:550

41. Cozens AL, Yezzi MJ, Kunzelmann K, Ohrui T, Chin L, Eng K, Finkbeiner WE, Widdicombe JH, Gruenert DC: CFTR expression and chloride secretion in polarized immortal human bronchial epithelial cells. Am J Respir Cell Mol Biol 1994, 10:38-47

42. Bandyopadhyay G, Huyck HL, Misra RS, Bhattacharya S, Wang Q, Mereness J, Lillis JA, Myers JR, Ashton J, Bushnell T, Cochran M, Holden-Wiltse J, Katzman P, Deutsch GH, Whitsett JA, Xu Y, Mariani TJ, Pryhuber GS: Dissociation, cellular isolation and initial molecular characterization of neonatal and pediatric human lung tissues. Am J Physiol Lung Cell Mol Physiol 2018, 315:1576-1583

43. Wang Q, Bhattacharya S, Mereness JA, Anderson C, Lillis JA, Misra RS, Romas S, Huyck H, Howell A, Bandyopadhyay G, Donlon K, Myers JR, Ashton J, Pryhuber GS, Mariani TJ: A novel in vitro model of primary human pediatric lung epithelial cells. Pediatr Res 2019, [Epub ahead of print] doi:10.1038/s41390-0190340-9

44. Godoy-Guzmán C, San Martin S, Pereda J: Proteoglycan and collagen expression during human air conducting system development. Eur J Histochem 2012, 56:e29

45. Nelson CM, Bissell MJ: Of extracellular matrix, scaffolds, and signaling: tissue architecture regulates development, homeostasis, and cancer. Annu Rev Cell Dev Biol 2006, 22:287-309

46. Upagupta C, Shimbori C, Alsilmi R, Kolb M: Matrix abnormalities in pulmonary fibrosis. Eur Respir Rev 2018, 27:180033

47. Bidan CM, Veldsink AC, Meurs H, Gosens R: Airway and extracellular matrix mechanics in COPD. Front Physiol 2015, 6:346

48. Foley AR, Quijano-Roy S, Collins J, Straub V, McCallum M, Deconinck N, Mercuri E, Pane M, D'Amico A, Bertini E, North K, Ryan MM, Richard P, Allamand V, Hicks D, Lamande S, Hu Y, Gualandi F, Auh S, Muntoni F, Bonnemann CG: Natural history of pulmonary function in collagen VI-related myopathies. Brain 2013, $136: 3625-3633$

49. Fraser KL, Wong S, Foley AR, Chhibber S, Bönnemann CG, Lesser DJ, Grosmann C, Rutkowski A: Pneumothoraces in collagen VI-related dystrophy: a case series and recommendations for management. ERJ Open Res 2017, 3:00049-2017
50. Warburton D, El-Hashash A, Carraro G, Tiozzo C, Sala F, Rogers O, De Langhe S, Kemp PJ, Riccardi D, Torday J, Bellusci S, Shi W, Lubkin SR, Jesudason E: Lung organogenesis. Curr Topics Dev Biol 2010, 90:73-158

51. Betz P, Nerlich A, Bussler J, Hausmann R, Eisenmenger W: Radial alveolar count as a tool for the estimation of fetal age. Int J Legal Med 1997, 110:52-54

52. Centanni R, Haraldsdottir K, Braun R, Barton G, Goss K, Eldridge M, Pegelow D: Increased alveolar size persists in a rodent model of bronchopulmonary dysplasia. FASEB J 2016, 30 Suppl: 1298.1

53. Knudsen L, Weibel ER, Gundersen HJG, Weinstein FV, Ochs M: Assessment of air space size characteristics by intercept (chord) measurement: an accurate and efficient stereological approach. J Appl Physiol 2009, 108:412-421

54. Jobe AH: The new bronchopulmonary dysplasia. Curr Opin Pediatr 2011, 23:167-172

55. Cescon M, Chen P, Castagnaro S, Gregorio I, Bonaldo P: Lack of collagen VI promotes neurodegeneration by impairing autophagy and inducing apoptosis during aging. Aging 2016, 8:1083-1101

56. Silberberg R, Silberberg M, Jarrett SR: Effects of diet during growth: studies in male mice of various strains. Pathol Microbiol 1962, 25: 56-66

57. Doyle LW, Carse E, Adams A-M, Ranganathan S, Opie G, Cheong JLY: Ventilation in extremely preterm infants and respiratory function at 8 years. N Engl J Med 2017, 377:329-337

58. Fawke J, Lum S, Kirkby J, Hennessy E, Marlow N, Rowell V, Thomas S, Stocks J: Lung function and respiratory symptoms at 11 years in children born extremely preterm the EPICure study. Am J Respir Crit Care Med 2010, 182:237-245

59. O'Reilly MA, Yee M, Buczynski BW, Vitiello PF, Keng PC, Welle SL, Finkelstein JN, Dean DA, Lawrence BP: Neonatal oxygen increases sensitivity to influenza A virus infection in adult mice by suppressing epithelial expression of ear1. Am J Pathol 2012, 181: $441-451$

60. Wikenheiser KA, Wert SE, Wispe JR, Stahlman M, D'AmoreBruno M, Singh G, Katyal SL, Whitsett JA: Distinct effects of oxygen on surfactant protein B expression in bronchiolar and alveolar epithelium. Am J Physiol 1992, 262:L32-L39

61. Yee M, Vitiello PF, Roper JM, Staversky RJ, Wright TW, McGrathMorrow SA, Maniscalco WM, Finkelstein JN, O'Reilly MA: Type II epithelial cells are critical target for hyperoxia-mediated impairment of postnatal lung development. Am J Physiol Lung Cell Mol Physiol 2006, 291:L1101-L1111

62. McGrath-Morrow SA, Cho C, Cho C, Zhen L, Hicklin DJ, Tuder RM: Vascular endothelial growth factor receptor 2 blockade disrupts postnatal lung development. Am J Respir Cell Mol Biol 2005, 32:420-427

63. Le Cras TD, Markham NE, Tuder RM, Voelkel NF, Abman SH: Treatment of newborn rats with a VEGF receptor inhibitor causes pulmonary hypertension and abnormal lung structure. Am J Physiol Lung Cell Mol Physiol 2002, 283:L555-L562

64. Tammela T, Zarkada G, Wallgard E, Murtomäki A, Suchting S, Wirzenius M, Waltari M, Hellström M, Schomber T, Peltonen R, Freitas C, Duarte A, Isoniemi H, Laakkonen P, Christofori G, YläHerttuala S, Shibuya M, Pytowski B, Eichmann A, Betsholtz C, Alitalo K: Blocking VEGFR-3 suppresses angiogenic sprouting and vascular network formation. Nature 2008, 454:656

65. Gomes M, Archer F, Girard N, Gineys B, Dolmazon C, Bobet Erny A, Mornex J-F, Leroux C: Blocked expression of key genes of the angiogenic pathway in JSRV-induced pulmonary adenocarcinomas. Vet Res 2017, 48:76

66. Wright C, Strauss S, Toole K, Burt AD, Robson SC: Composition of the pulmonary interstitium during normal development of the human fetus. Pediatr Dev Pathol 1999, 2:424-431

67. Sadati M, Taheri Qazvini N, Krishnan R, Park CY, Fredberg JJ: Collective migration and cell jamming. Differentiation 2013, 86:121-125 
68. Park J-A, Atia L, Mitchel JA, Fredberg JJ, Butler JP: Collective migration and cell jamming in asthma, cancer and development. J Cell Sci 2016, 129:3375-3383

69. Plosa EJ, Young LR, Gulleman PM, Polosukhin VV, Zaynagetdinov R, Benjamin JT, Im AM, van der Meer R, Gleaves LA, Bulus N, Han W, Prince LS, Blackwell TS, Zent R: Epithelial $\beta 1$ integrin is required for lung branching morphogenesis and alveolarization. Development 2014, 141:4751-4762

70. Kleinman HK, Martin GR: Matrigel: basement membrane matrix with biological activity. Semin Cancer Biol 2005, 15:378-386
71. Hughes CS, Postovit LM, Lajoie GA: Matrigel: a complex protein mixture required for optimal growth of cell culture. Proteomics 2010, 10:1886-1890

72. López-Colomé AM, Lee-Rivera I, Benavides-Hidalgo R, López E: Paxillin: a crossroad in pathological cell migration. J Hematol Oncol 2017, 10:50

73. Diaz-Munoz MD, Osma-Garcia IC, Iniguez MA, Fresno M: Cyclooxygenase-2 deficiency in macrophages leads to defective p110gamma PI3K signaling and impairs cell adhesion and migration. J Immunol 2013, 191:395-406 